\title{
Needle-injectable microcomposite cryogel scaffolds with antimicrobial properties
}

\author{
Kasturi Joshi Navare ${ }^{1}$, Thibault Colombani ${ }^{1}$, Mahboobeh Rezaeeyazdi ${ }^{1}$, Nicole Bassous ${ }^{1}$, \\ Devyesh Rana ${ }^{1}$, Thomas Webster ${ }^{1,2}$, Adnan Memic ${ }^{3}$ \& Sidi A. Bencherif ${ }^{1,4,5,6 凹}$
}

Porous three-dimensional hydrogel scaffolds have an exquisite ability to promote tissue repair. However, because of their high water content and invasive nature during surgical implantation, hydrogels are at an increased risk of bacterial infection. Recently, we have developed elastic biomimetic cryogels, an advanced type of polymeric hydrogel, that are syringe-deliverable through hypodermic needles. These needle-injectable cryogels have unique properties, including large and interconnected pores, mechanical robustness, and shape-memory. Like hydrogels, cryogels are also susceptible to colonization by microbial pathogens. To that end, our minimally invasive cryogels have been engineered to address this challenge. Specifically, we hybridized the cryogels with calcium peroxide microparticles to controllably produce bactericidal hydrogen peroxide. Our novel microcomposite cryogels exhibit antimicrobial properties and inhibit antibiotic-resistant bacteria (MRSA and Pseudomonas aeruginosa), the most common cause of biomaterial implant failure in modern medicine. Moreover, the cryogels showed negligible cytotoxicity toward murine fibroblasts and prevented activation of primary bone marrow-derived dendritic cells ex vivo. Finally, in vivo data suggested tissue integration, biodegradation, and minimal host inflammatory responses when the antimicrobial cryogels, even when purposely contaminated with bacteria, were subcutaneously injected in mice. Collectively, these needle-injectable microcomposite cryogels show great promise for biomedical applications, especially in tissue engineering and regenerative medicine.

The goals of tissue engineering are centered on the repair or replacement of diseased or damaged tissue by using a combination of scaffolds, cells, and signaling (i.e., biochemical and biophysical) cues ${ }^{1-5}$. Three-dimensional (3D) scaffolds are designed to provide a structural support and physical environment for cell attachment and subsequent tissue development ${ }^{6-9}$. Various biomaterials have been utilized to fabricate bioactive scaffolds with tunable physicochemical properties (e.g., rigidity, elasticity, and biodegradation) while exhibiting remarkable biocompability ${ }^{10-13}$. For instance, hydrogels, cross-linked networks made from synthetic and/or naturally occurring hydrophilic polymers, absorb and hold large amounts of water while retaining their 3D integrity and mimicking the native cellular microenvironment ${ }^{14-26}$. To match the mechanical properties of human tissues, from soft to more rigid, several strategies have been investigated to tune gel stiffness ${ }^{10,27,28}$. Amongst the methods available are (i) adjusting the cross-linking density (e.g., cross-linking agents, polymer concentration), (ii) implementing a double network hydrogel system (e.g., interpenetrating polymer network), and (iii) hybridizing hydrogels with composite materials (e.g., carbon nanotubes, graphene oxide) $)^{10,29-31}$.

Recently, injectable hydrogels, such as shear-thinning or in situ gelling hydrogels, have been developped to prevent trauma and other complications associated with the invasive nature of surgical implantations ${ }^{28,32,33}$. Yet, these non-invasive hydrogels face a number of challenges, including the delivery of large preformed hydrogels and the control over their microstructural features (i.e., pore size) to facilitate cellular infiltration and molecular diffusion of proteins, oxygen, and nutrients/waste products ${ }^{28,33-36}$. To address these challenges, cryogels, a type of macroporous hydrogels with unique properties, have been fabricated via cryopolymerization at subzero temperatures. These gels have large macroscale interconnected pores and improved mechanical properties compared

\footnotetext{
${ }^{1}$ Department of Chemical Engineering, Northeastern University, Boston, MA 02115, USA. ${ }^{2}$ Wenzhou Institute for Biomaterials and Engineering, Wenzhou 325001, China. ${ }^{3}$ Center of Nanotechnology, King Abdulaziz University, Jeddah 21589, Saudi Arabia. ${ }^{4}$ Department of Bioengineering, Northeastern University, Boston, MA 02115, USA. ${ }^{5}$ Sorbonne University, UTC CNRS UMR 7338, Biomechanics and Bioengineering (BMBI), University of Technology of Compiègne, 60203 Compiègne, France. ${ }^{6}$ Harvard John A. Paulson School of Engineering and Applied Sciences, Harvard University, Cambridge, MA 02138, USA. ${ }^{\varpi}$ email: s.bencherif@northeastern.edu
} 
to their mesoporous hydrogel counterparts ${ }^{37-43}$. These architectural features can allow easier nutrient inflow and waste removal, both of which are important in tissue engineering applications ${ }^{42,44}$. Furthermore, the highly dense polymer walls and large pores allow cryogels to undergo reversible compression (i.e., up to $90 \%$ of the initial volume $)^{37,42,44,45}$. These cryogels have shape-memory properties and can undergo injection through hypodermic needles without any structural damage, allowing their minimally invasive delivery into the body ${ }^{17,33,46,47}$. A variety of biopolymers have been used to fabricate biomimetic cryogels for tissue engineering applications ${ }^{48-53}$.

Over the past years, biomaterials made from extracellular matrix (ECM) components have been used to better recapitulate native tissue microenvironments ${ }^{54}$. One component of the ECM and an important constituent of synovial fluid is hyaluronic acid (HA), a linear polysaccharide made from unbranched recurring components of $\mathrm{N}$-acetylglucosamine and glucuronic acid. Furthermore, HA has been shown to play an important role in several cellular processes, such as wound healing and angiogenesis ${ }^{30,55}$. Biomaterial scaffolds made from HA precursors have been used to engineer various tissues ${ }^{56,57}$. HA-based biomaterials are generally nonimmunogenic, promote long-term water retention, and exhibit good flexibility ${ }^{56,58}$. However, the growing incidence of antibiotic-resistant infections remains a major challenge when designing implantable biomaterials ${ }^{37,59,60}$.

The U.S. Centers for Disease Control and Prevention (CDC) reported that over 100,000 biomaterial and surgical site infections occurred in 2011 alone ${ }^{61}$. Common biomedical implant-related pathogens include Staphylococcus aureus (S. aureus), Escherichia coli (E. coli), and Pseudomonas aeruginosa ( $P$. aeruginosa). Complications from implant-related infections can impede tissue regeneration, delay wound healing ${ }^{59}$, and induce the development of biofilms that can require $>1000$ times higher doses of antibiotics for effective treatments ${ }^{16,62-64}$. To address this challenge, diverse strategies have been deployed to prevent microbial contamination of biomaterials. Some of the strategies have relied on developing antibiotic-containing surface coatings or incorporating antimicrobial peptides within biomaterial constructs ${ }^{46,62,64-69}$. However, a number of limitations of these approaches still remain. For example, the use of antiadhesive coatings can hinder cell attachment and lead to poor tissue integration. Similarly, the overuse of antimicrobial peptides poses the risk of increased bacterial resistance $e^{47,66,67,70}$. Zhao et al. developed antimicrobial cryogels fabricated from chitosan ${ }^{70}$. However, scaffolds made with polycations such as chitosan are known to be proinflammatory with slow in vivo degradation ${ }^{71,72}$. Adverse host immune reactions of biomaterials can impair healing and result in implant isolation (e.g., fibrotic encapsulation) and ultimately rejection ${ }^{73}$. To address this shortcoming, researchers have turned to the incorporation of nanomaterials such as metal and metal oxide nanoparticles ${ }^{74,75}$ to improve the antibacterial activity of cryogels. However, the incorporation of metallic nanoparticles has also been associated with decreased mammalian cell proliferation and viability $^{76,77}$. For instance, Chaturvedi et al. incorporated antimicrobial zinc oxide $(\mathrm{ZnO})$ nanoparticles into polyvinyl alcohol cryogels and studied their biocompatibility ${ }^{78}$. They reported that at high concentration, $\mathrm{ZnO}$ nanoparticles can induce hemolysis, a condition leading to the breakdown of red blood cells. Similarly, Zou et al. incorporated silver (Ag) nanoparticles into chitosan-poly(ethylene glycol) cryogels ${ }^{69}$. Even though their composite cryogels exhibited improved antibacterial activity, the effect of Ag nanoparticles on mammalian cells was not studied.

One recent alternative strategy is the development of nanocomposite biomaterials that have intrinsic antimicrobial properties. Recently, Zhao et al. developed nanocomposite cryogels that had antibacterial properties and could be used for non-compressible hemorrhage and wound healing ${ }^{70}$. Specifically, they fabricated a group of carbon nanotube-reinforced chitosan-based cryogels that were syringe injectable and conductive. However, their platform was not able to be delivered using minimally invasive methods (i.e., needle-injectable) and was built using polycations that are generally reported to be proinflammatory in vivo ${ }^{71}$. Furthermore, quaternized chitosan has limited in vivo degradation. Another example was reported by Wang et al. 2010, who developed antimicrobial calcium peroxide (CP)-incorporated polycaprolactone nanofibers. These CP particles can release oxygen and other oxygen species to support tissue engineering and wound healing platforms ${ }^{63,79,80}$. Specifically, $\mathrm{CP}$ dissociates to form calcium hydroxide and hydrogen peroxide (Eq. 1), which can further decompose and lead to the release of hydroxyl ions (Eq. 2), elevation of $\mathrm{pH}$, and free radical-mediated antifungal ${ }^{81}$, antiviral ${ }^{82}$, and antibacterial effects ${ }^{83-85}$.

$$
\begin{gathered}
\mathrm{CaO}_{2}+2 \mathrm{H}_{2} \mathrm{O} \rightarrow \mathrm{Ca}(\mathrm{OH})_{2}+\mathrm{H}_{2} \mathrm{O}_{2} \\
\mathrm{Ca}(\mathrm{OH})_{2} \rightarrow \mathrm{Ca} \downarrow+2 \mathrm{OH}^{-} \text {and } \mathrm{H}_{2} \mathrm{O}_{2} \rightarrow \mathrm{OH}^{-}+\mathrm{OH} \bullet
\end{gathered}
$$

In this study, we fabricated antimicrobial cryogels using methacrylated hyaluronic acid (HAGM) hybridized with CP microparticles at different concentrations (Fig. 1). These microcomposite cryogels exhibited a highly interconnected and dense polymer network that can collapse and be injected through a $16 \mathrm{G}$ needle without any mechanical damage (Supplementary Movies 1 and 2). We investigated changes in the physical properties of these cryogels as a result of CP incorporation. Specifically, we determined the effects of CP inclusion on cryogel pore size distribution, interconnectivity, swelling, and mechanical properties. We monitored the release of hydrogen peroxide from CP present within the cryogel scaffolds and how the concentration of CP within the cryogels affected their antibacterial activity. We assessed the antibacterial activity using some of the most virulent bacterial pathogens (i.e., superbugs), including methicillin-resistant Staphylococcus aureus (MRSA) and $P$. aeruginosa. Next, we assessed the cytocompatibility of cryogels using NIH/3T3 mouse fibroblasts (i.e., cell viability) and the in vitro immunogenic response (i.e., dendritic cell activation) using both CP-free and CPcontaining cryogels. Finally, the in vivo biodegradation and immunogenic response across the cryogels were evaluated using C57BL/6 mice. 


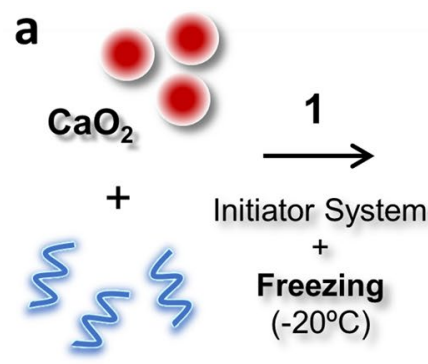

HAGM

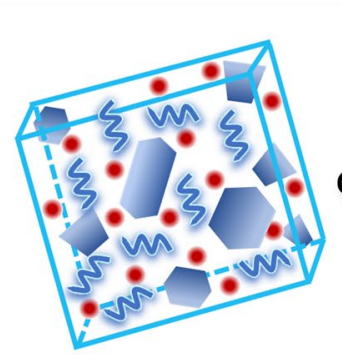

Large
Interconnected
Pores

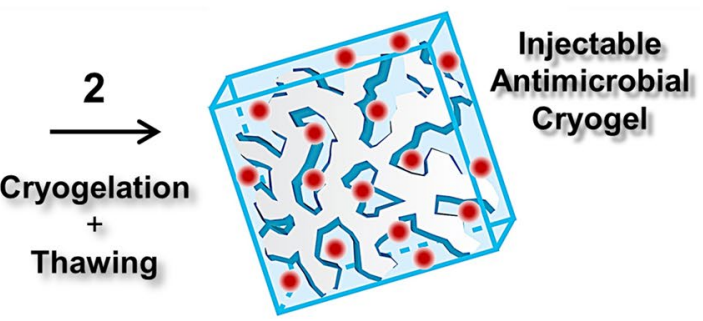

b
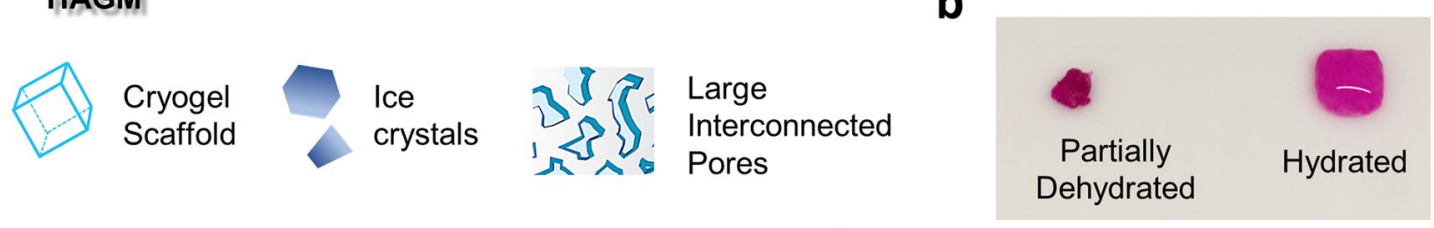

C

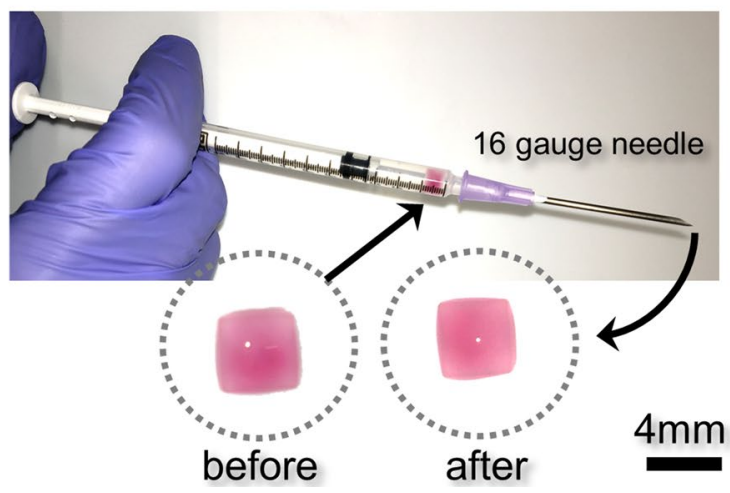

d

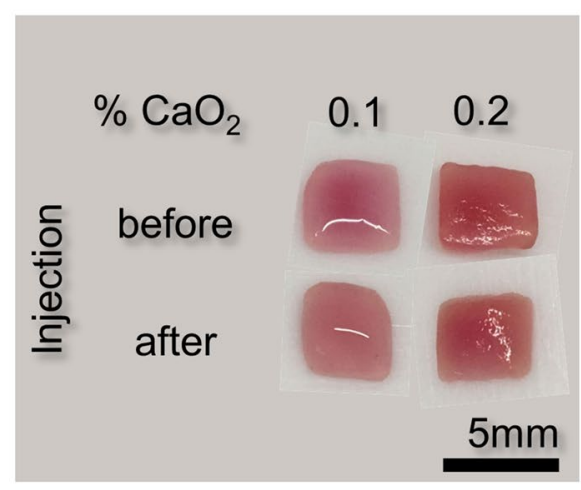

Figure 1. Engineering antimicrobial and injectable microcomposite cryogels. (a) Overview of the fabrication process of antimicrobial CP-containing injectable cryogels: (1) cryogels were fabricated using 4\% HAGM with different amounts of $\mathrm{CP}\left(0-0.2 \% \mathrm{CaO}_{2}\right)$; an initiator system (APS/TEMED) is added to an aqueous HAGM solution prior to cryopolymerization at $-20^{\circ} \mathrm{C}$. (2) Cryotreatment involves phase separation with ice crystal formation, cross-linking and gelation. Thawing of ice crystals (porogens) results in an interconnected macroporous cryogel network. (b) Cryogel partially dehydrated over Kimwipe regains its original shape and size after hydration. HAGM cryogels were stained with rhodamine for visualization. (c) Following injection through a $16 \mathrm{G}$ hypodermic needle, cryogels regain their original shape and dimensions. (d) Cryogels retain their encapsulated CP after needle injection as indicated by the Alizarin Red S staining $(n=5)$.

\section{Results}

Characterization of cryogels. We first characterized the mechanical and structural properties of the fabricated cryogels. Specifically, we examined three cryogel formulations, the first without any $\mathrm{CP}$ (i.e., $0 \% \mathrm{CaO}_{2}$ ); the second with $0.1 \%(\mathrm{w} / \mathrm{v}) \mathrm{CP}$ (i.e., $0.1 \% \mathrm{CaO}_{2}$ ); and the third prepared with a $0.2 \%(\mathrm{w} / \mathrm{v}) \mathrm{CP}$ (i.e., $0.2 \% \mathrm{CaO}_{2}$ ). We first assessed how the cryogel swelling ratio varied as a function of $\mathrm{CP}$ concentration. We observed that all cryogel swelling ratios ranged from $\mathrm{Q}_{M}=41$ to 45 , remaining relatively unchanged regardless of the amount of CP incorporated (Fig. 2a). Next, we measured the compressive moduli for each cryogel formulation. The comparison of the compressive moduli revealed that all cryogels exhibited low compressive moduli of approximately $2.2 \mathrm{kPa}$ (Fig. 2b). Similarly, the pore interconnectivity of the cryogels was high (i.e., $~ 80 \%$ ) and remained similar across the investigated CP concentrations (Fig. 2c).

We next characterized the morphological features of the cryogels. Scanning electron microscopy (SEM) imaging show that after cryogelation, a network of large interconnected pores remains (Fig. $2 \mathrm{~d}-\mathrm{f}$ ). Overall, the cryogels displayed a continuous, uniform network of interconnected macropores, with the presence of solid CP particles $\left(0.1-0.2 \% \mathrm{CaO}_{2}\right)$ embedded within the polymer network (Fig. 2 h,i). Finally, the average pore sizes ranged from 25 to $30 \mu \mathrm{m}$ (Fig. $2 \mathrm{~g}-\mathrm{i}$ ) with a similar pore size distribution patterns (Fig. 2j-l) among all three cryogel formulations. Data are presented as the mean \pm standard error of the mean $(n=4)$.

Kinetics of hydrogen peroxide release from cryogels. Hydrolysis of the CP particles entrapped within the cryogels leads to the formation of hydrogen peroxide. The release profile of hydrogen peroxide within the first $5 \mathrm{~h}$ was compared between the two (i.e., $0.1 \%$ vs $0.2 \% \mathrm{CaO}_{2}$ ) square-shaped cryogels (dimensions: $4 \mathrm{~mm} \times 4 \mathrm{~mm} \times 1 \mathrm{~mm})$. Both cryogel variants showed similar release patterns with over $60 \%$ release within the first 15 min followed by a progressively decreasing release pattern within the next $3 \mathrm{~h}$. The $0.1 \% \mathrm{CaO}_{2}$ cryogels 

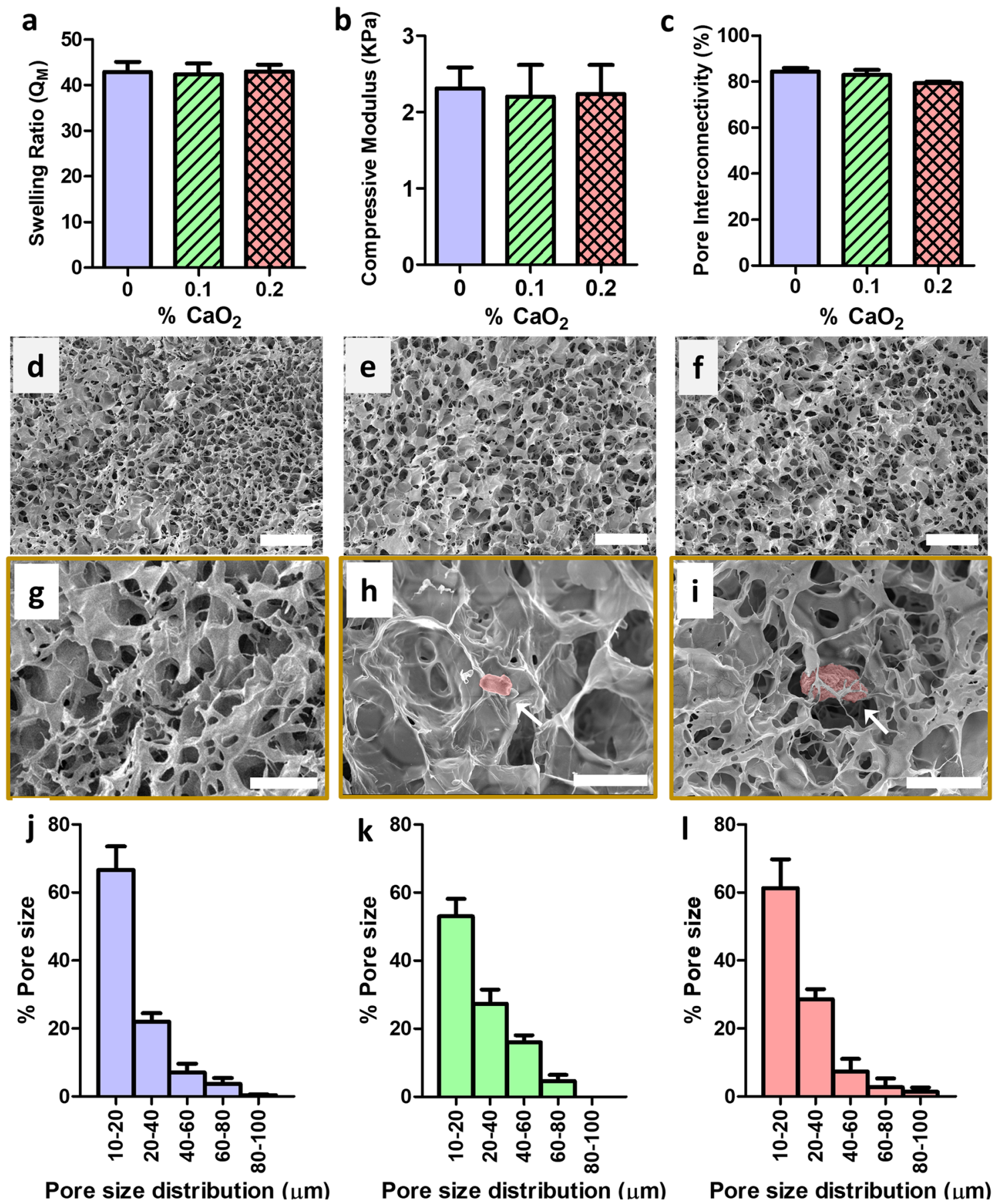

Pore size distribution (um)

Pore size distribution (um)

Figure 2. Antimicrobial cryogels have advantageous mechanical properties and microarchitectural features. A total of three types of cryogels were fabricated using $4 \%$ HAGM and different amounts of $\mathrm{CP}\left(0-0.2 \% \mathrm{CaO}_{2}\right) .(\mathbf{a})$ swelling ratio, (b) Young's moduli, and (c) evaluation of pore connectivity. Cross-sectional SEM images showing interconnected macroporous network of (d) CP-free cryogels $\left(0 \% \mathrm{CaO}_{2}\right)$, (e) CP-containing $\left(0.1 \% \mathrm{CaO}_{2}\right)$ cryogels, and (f) CP-containing $\left(0.2 \% \mathrm{CaO}_{2}\right)$ cryogels. SEM samples $(\mathrm{n}=3)$ were scanned and representative images have been presented. Cross-sectional SEM images for visualization of CP (pseudocolored in pink): (g) CP-free cryogel $\left(0 \% \mathrm{CaO}_{2}\right)$, (h) CP-containing $\left(0.1 \% \mathrm{CaO}_{2}\right)$ cryogel, and (i) CP-containing $\left(0.2 \% \mathrm{CaO}_{2}\right)$ cryogel. Pore size distribution histograms of $(\mathbf{j}) \mathrm{CP}$-free cryogels $\left(0 \% \mathrm{CaO}_{2}\right),(\mathbf{k}) \mathrm{CP}$-containing $\left(0.1 \% \mathrm{CaO}_{2}\right)$ cryogels, and (l) CP-containing $\left(0.2 \% \mathrm{CaO}_{2}\right)$ cryogels. Scale bars $=100 \mu \mathrm{m}(\mathrm{d}, \mathrm{e}$, and f) and $50 \mu \mathrm{m}(\mathrm{g}, \mathrm{h}$, and i). 
a

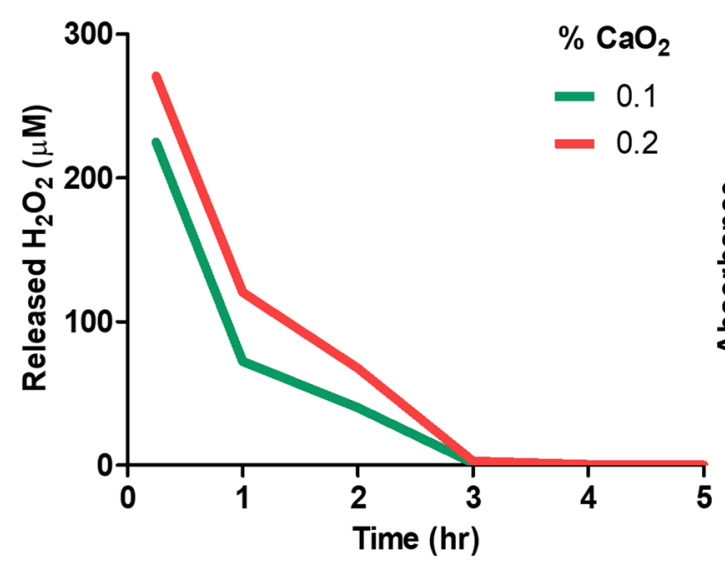

b

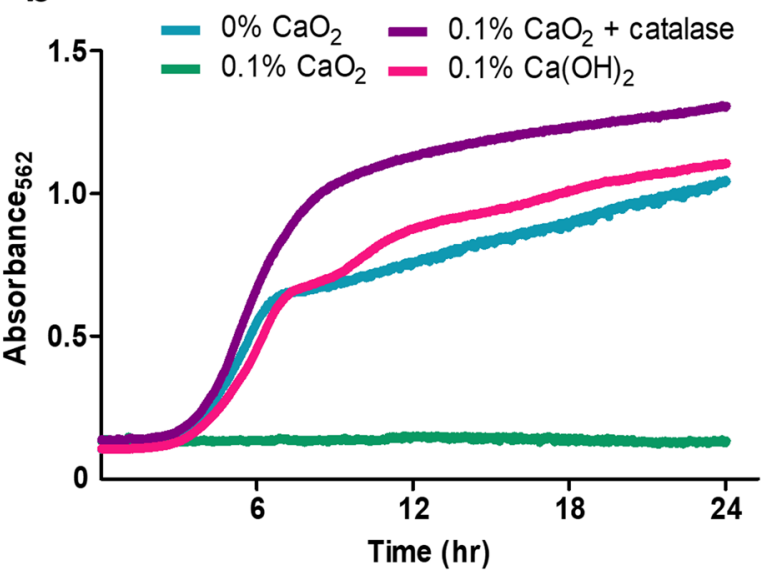

C

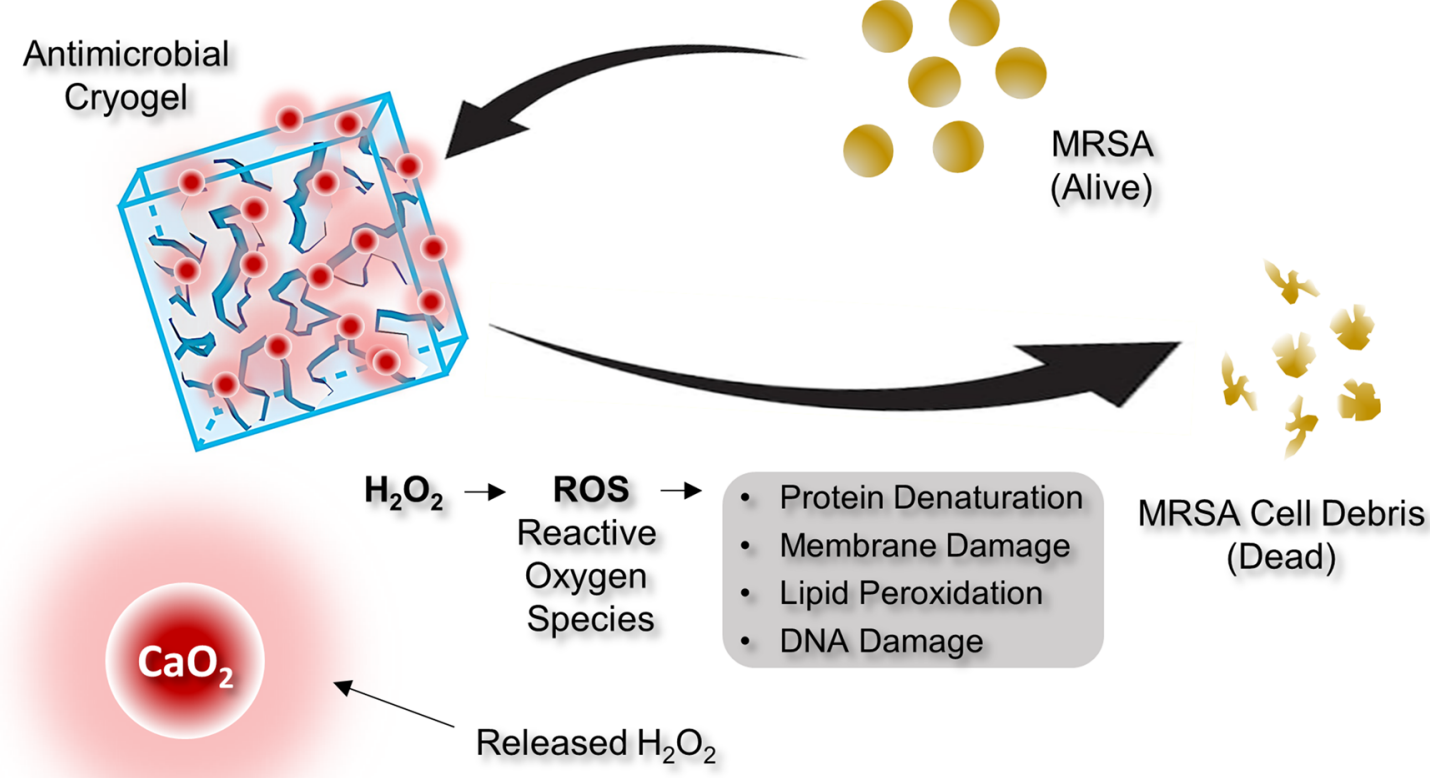

Figure 3. CP-containing cryogels generate antimicrobial hydrogen peroxide $\left(\mathrm{H}_{2} \mathrm{O}_{2}\right)$. (a) Release of $\mathrm{H}_{2} \mathrm{O}_{2}$ from the cryogels following injection through a $16 \mathrm{G}$ needle, $n=3$. (b) Growth monitoring absorbance values of MRSA after $24 \mathrm{~h}$ of incubation with $\mathrm{CP}$ alone, $\mathrm{CP}$ with catalase and $\mathrm{Ca}(\mathrm{OH})_{2}$ along with a control $(\mathrm{CP}$-free medium), average values of three experiments have been plotted. (c) Schematic representing the biocidal action of CP-containing cryogels against bacteria.

Another byproduct of $\mathrm{CP}$ hydrolysis is calcium hydroxide (i.e., $\mathrm{Ca}(\mathrm{OH})_{2}$ ) precipitate which has been reported to have limited antibacterial properties. We next compared the effect of hydrogen peroxide and calcium hydroxide on MRSA growth. The bacterial growth was monitored for $24 \mathrm{~h}$ using culture broth containing CP, CP supplemented with bovine catalase, and calcium hydroxide. The role of catalase was to break down hydrogen peroxide into water and oxygen, and as a result, neutralizing its antibacterial effect ${ }^{86}$. We observed bacterial growth inhibition only in the presence of CP, while MRSA grew unhindered under the other conditions. This result suggests that the antibacterial activity of CP is predominantly based on hydrogen peroxide activity and that calcium hydroxide had minimal or no effect on bacteria (Fig. 3b,c).

Antibacterial activity of microcomposite CP-containing cryogels. Two pathogens (i.e., MRSA and $P$. aeruginosa) were used to study the antibacterial properties of cryogels hybridized with CP. First, partially dehydrated cryogels were contaminated with a known density of bacteria [i.e., colony forming units (CFUs)]. After $6 \mathrm{~h}$ of bacterial incubation within the cryogels, the number of CFUs was quantified. Figure 4a-c shows the trend observed for MRSA incubated with CP-free and CP-containing cryogels. In the absence of CP particles, bacteria within the cryogels not only remained viable but also underwent growth and expansion. On the other hand, cryogels containing $0.1-0.2 \% \mathrm{CP}$ exhibited total bacterial growth inhibition. Similar findings were observed in the case of $P$. aeruginosa (Fig. $4 \mathrm{~d}-\mathrm{f})$. For example, in the case of CP-free $\left(0 \% \mathrm{CaO}_{2}\right)$ cryogels, the 
a
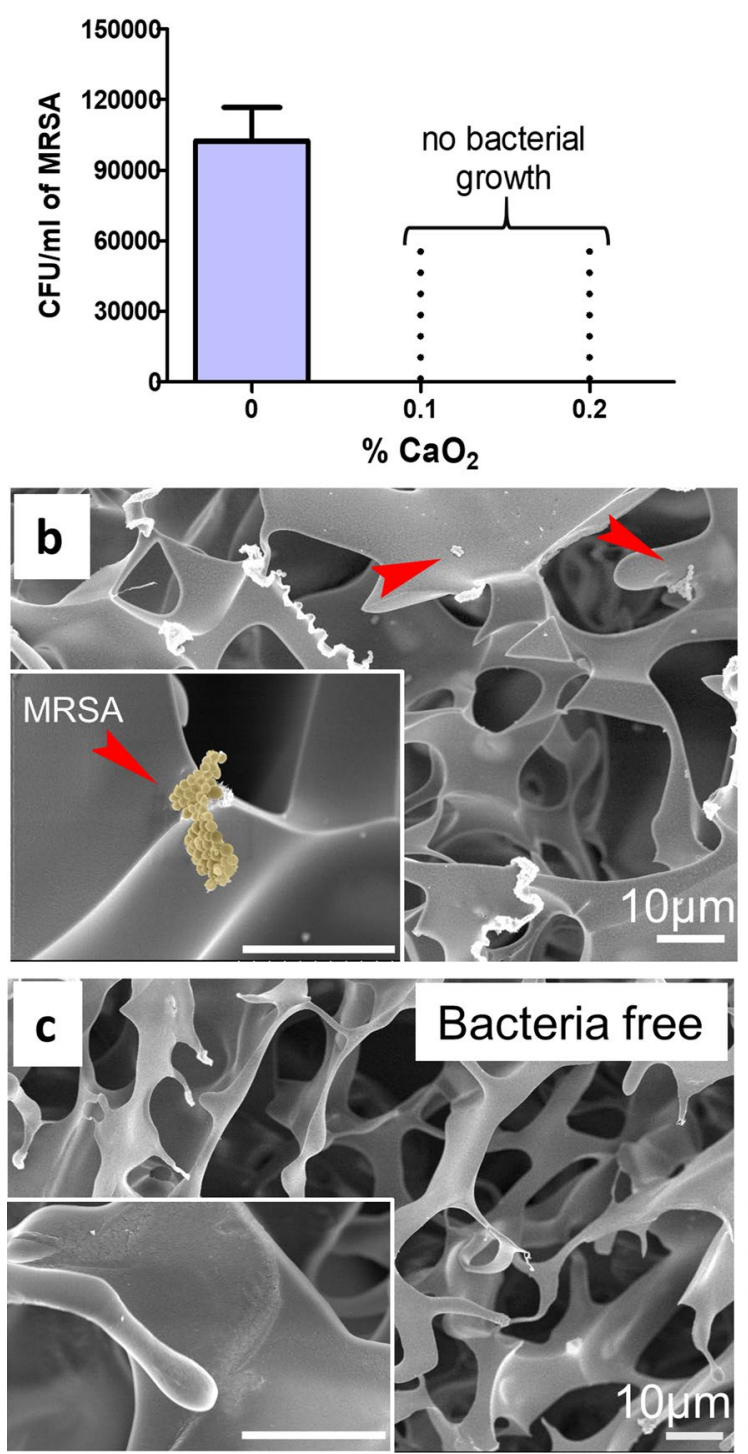

d
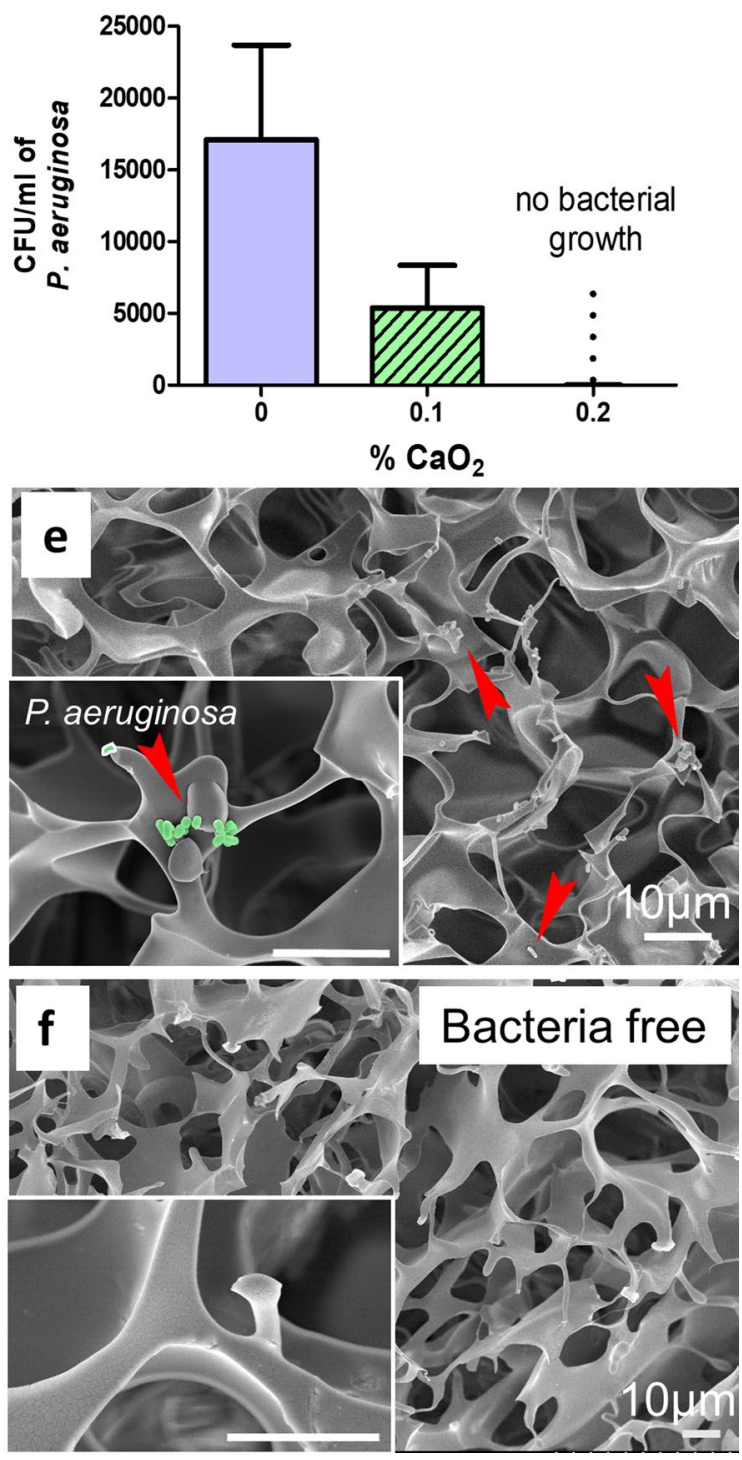

Figure 4. Antibacterial activity of CP-containing microcomposite cryogels. (a) Residual CFU i.e., colony forming units per $\mathrm{ml}$ of MRSA after $6 \mathrm{~h}$ of contact period within different cryogels; namely CP-free cryogels $(0 \%$ $\left.\mathrm{CaO}_{2}\right), \mathrm{CP}$-containing $\left(0.1 \% \mathrm{CaO}_{2}\right)$ cryogels, and CP-containing $\left(0.2 \% \mathrm{CaO}_{2}\right)$ cryogels. (b) Cross-sectional SEM of CP-free cryogels $\left(0 \% \mathrm{CaO}_{2}\right)$, and (c) CP-containing $\left(0.1 \% \mathrm{CaO}_{2}\right)$ cryogels. (d) Residual CFU/ml P. aeruginosa after $6 \mathrm{~h}$ of contact period across different cryogels. (e) cross-sectional SEM of CP-free cryogel $\left(0 \% \mathrm{CaO}_{2}\right)$, and (f) $\mathrm{CP}$-containing $\left(0.2 \% \mathrm{CaO}_{2}\right)$ cryogels. Data are representative of three independent experiments and are presented as the mean \pm standard error of the mean $(n=4)$. For visualization, MRSA and P. aeruginosa were pseudocolored in yellow and green, respectively. Scale bars $=10 \mu \mathrm{m}$.

number of CFUs significantly increased, whereas cryogels containing $0.2 \%$ CP displayed total bacterial inhibition. However, cryogels containing $0.1 \% \mathrm{CP}$ were not as effective against $P$. aeruginosa as they were with MRSA, showing that approximately half of the P. aeruginosa remained viable after $6 \mathrm{~h}$ (Supplementary Figs. 1 and 2). The antibacterial activity of CP-containing cryogels was also further tested against other multi-drug resistant bacteria, namely E. coli and Streptococcus pyogenes (Supplementary Figs. 3 and 4).

To visually check for the presence of bacteria, cryogels were fixed and imaged by SEM. Figure $4 \mathrm{~b}$ shows the presence of MRSA within $\mathrm{CaO}_{2}$-free cryogels. Conversely, Fig. 4c depicts the absence of bacteria within cryogels containing $0.1 \%$ CP. Similarly, the presence of $P$. aeruginosa can be seen in $\mathrm{CaO}_{2}$-free cryogels (Fig. $4 \mathrm{e}$ ) but was absent for cryogels containing $0.2 \% \mathrm{CP}$ (Fig. 4f), clearly demonstrating the antibacterial potential of microcomposite CP-containing cryogels.

In vitro cytocompatibility studies of antimicrobial cryogels. We next evaluated the cytotoxicity of the antibacterial cryogels using mouse fibroblasts NIH/3T3 cells. Specifically, after $24 \mathrm{~h}$ of incubation, cell attachment to the cryogels was observed by confocal microscopy. All CP-free and CP-containing cryogels (0.1- 

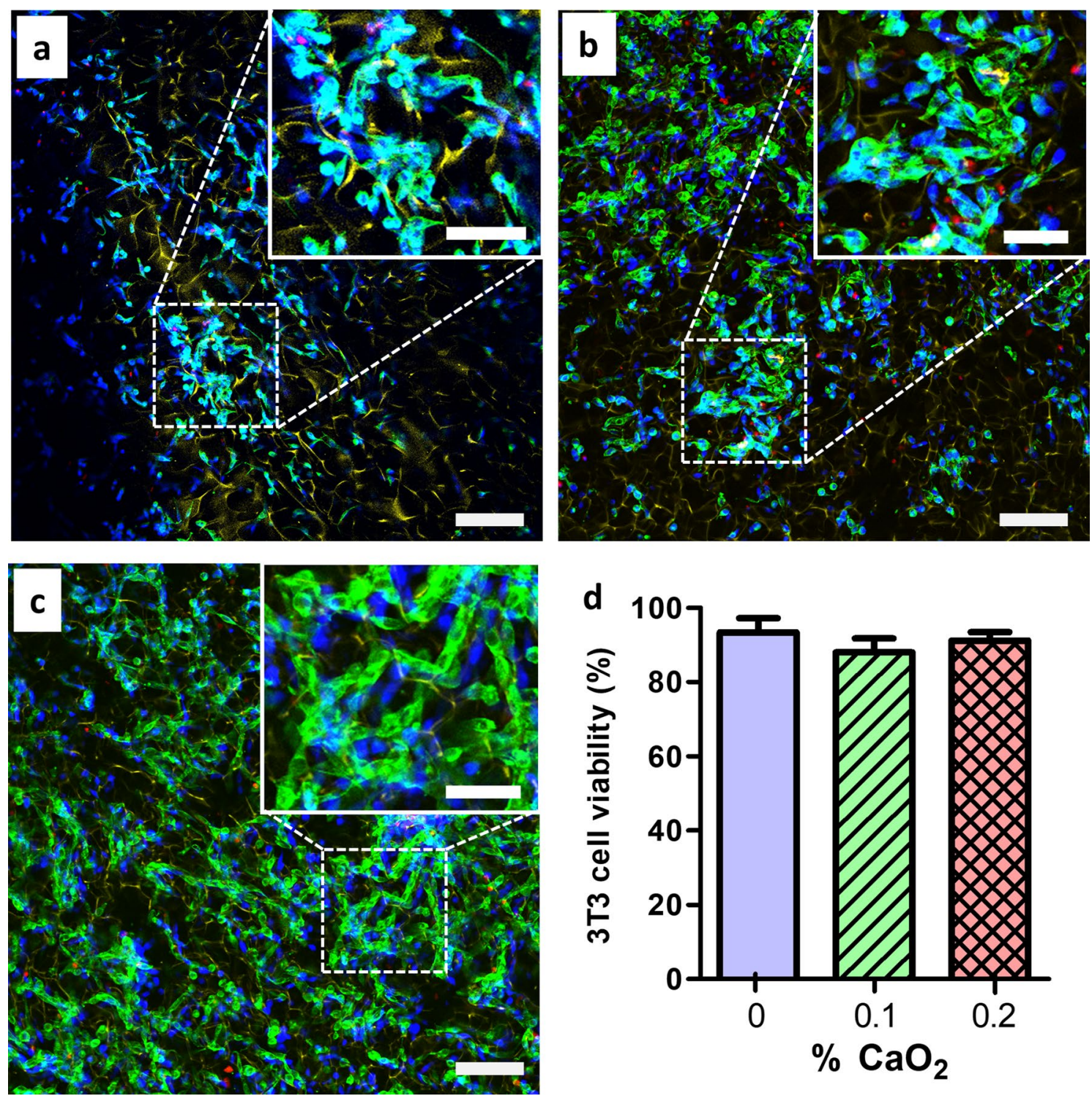

Figure 5. Antimicrobial CP-containing cryogels are cytocompatible towards murine fibroblasts. Confocal images showing mouse embryonic fibroblast NIH/3T3 cells cultured for $24 \mathrm{~h}$ in three CP-containing HAGM cryogels: (a) $0 \%$, (b) $0.1 \%$, and (c) $0.2 \% \mathrm{CaO}_{2}$. Red color depicts dead cells, blue color represents cell nuclei, green color highlights cell cytoskeleton and yellow color shows the polymer network of cryogels. (d) Evaluation of NIH/3T3 cell viability (\%). Scale bars $=200 \mu \mathrm{m}$ (large confocal images) and $100 \mu \mathrm{m}$ (inset confocal images). Data are presented as the mean \pm standard error of the mean $(n=4)$.

$0.2 \% \mathrm{CaO}_{2}$ ) supported the proliferation and attachment of cells along the polymer walls (Fig. $5 \mathrm{a}-\mathrm{c}$ ). We observed high cell viability (i.e., 90\%) for all cryogels (Fig. 5d). These findings indicate that antibacterial cryogels release enough hydrogen peroxide to kill bacterial pathogens but that the level released is below the toxicity threshold of a commonly used mammalian cell line.

In vitro immunogenic response of antimicrobial cryogels. Dendritic cells (DCs) are antigen-presenting cells that can play a crucial role in mounting an effective immune response. They secrete an array of proinflammatory cytokines, some of which are responsible for $\mathrm{T}$ cell differentiation ${ }^{76,77}$. Immunogenicity with bone marrow-derived DCs (BMDCs) was assessed using all three cryogel formulations. We further compared BMDC stimulation with cryogel-free (negative control) and lipopolysaccharide (LPS)-containing (positive control) media. Fractions of activated $\mathrm{CD} 11 \mathrm{c}^{+} \mathrm{CD} 86^{+}$and $\mathrm{CD} 11 \mathrm{c}^{+} \mathrm{MHCII}^{+} \mathrm{BMDCs}$ were measured by immunostaining in conjunction with fluorescence-activated cell sorting (FACS) analysis. CP-containing cryogels induced basal expression levels of CD86 and MHCII receptors nearly equivalent to those induced by the negative control (Fig. 6a-c). Finally, we characterized cell culture supernatants by ELISA for the DC-mediated secretion of several proinflammatory cytokines. In good agreement with the minimally activated DCs, the depicted low 
a

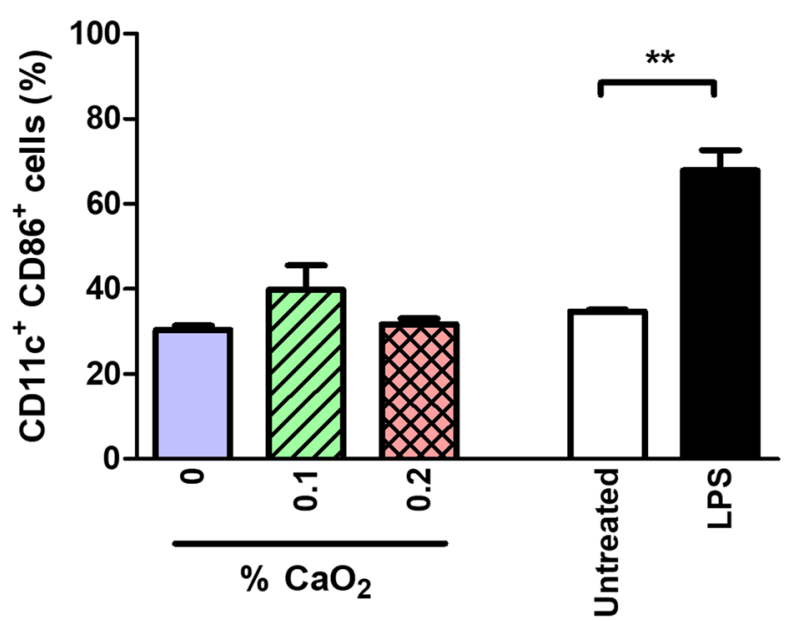

b

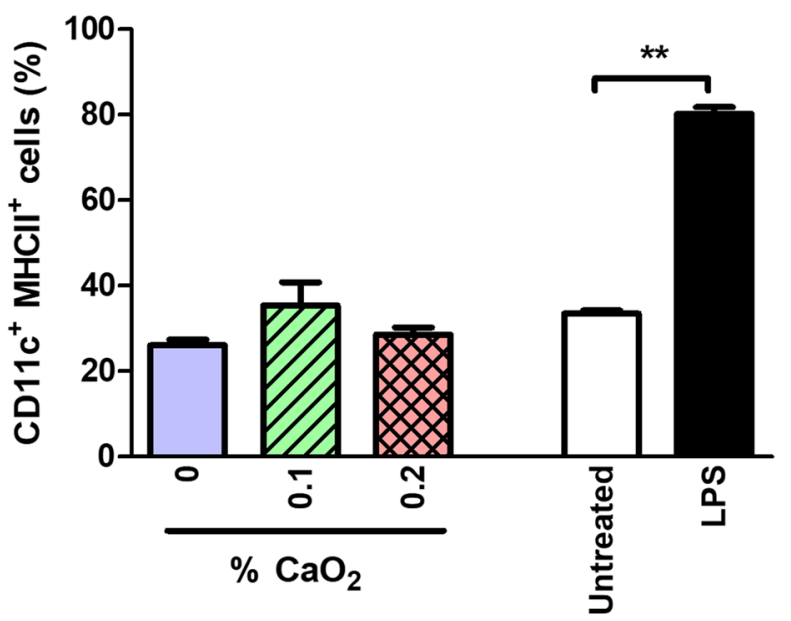

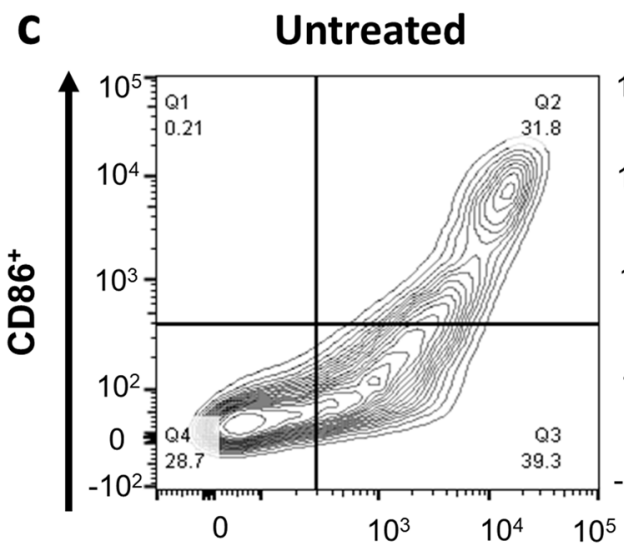

$\mathrm{CaO}_{2}$-containing Cryogels

LPS
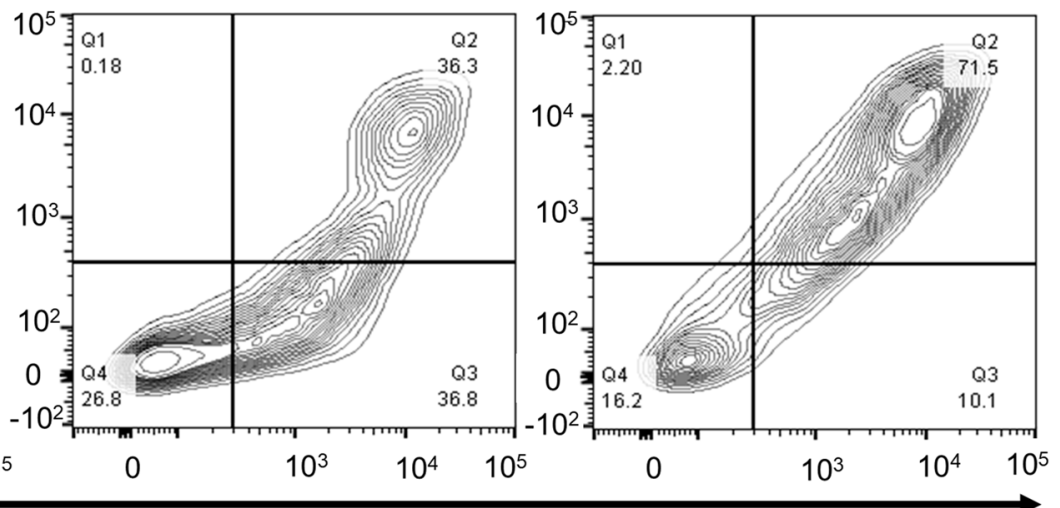

d

e

$\mathrm{MHClI}^{+}$
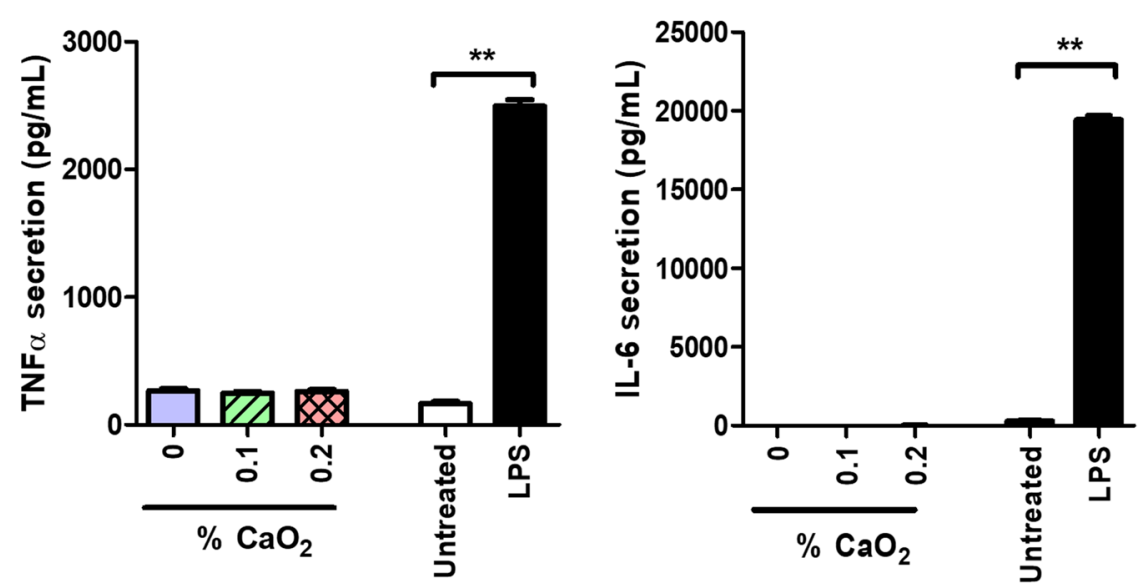

f

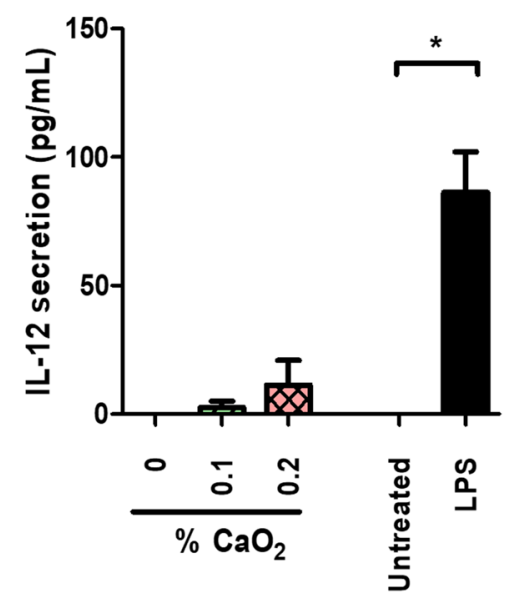

Figure 6. Antimicrobial CP-containing cryogels do not activate BMDCs. BMDCs were cultured for $24 \mathrm{~h}$ in the following conditions: in the presence of CP-free cryogels $\left(0 \% \mathrm{CaO}_{2}\right), \mathrm{CP}$-containing $\left(0.1 \% \mathrm{CaO}_{2}\right)$ cryogels, CP-containing $\left(0.2 \% \mathrm{CaO}_{2}\right)$ cryogels, cryogel-free medium (untreated, negative control) and LPS-containing medium ( $100 \mathrm{ng} / \mathrm{mL}$, positive control). Fractions of activated (a) CD $11 \mathrm{c}^{+} \mathrm{CD} 86^{+} \mathrm{BMDCs}$ and (b) CD $11 \mathrm{c}^{+}$ $\mathrm{MHCII}^{+}$BMDCs after $24 \mathrm{~h}$ of incubation in the different conditions. (c) Expression profile of CD86 and $\mathrm{MHCII}$ in CD11c $\mathrm{c}^{+} \mathrm{DCs}$. The results shown are representative of 4 independent experiments. Concentrations of DC-secreted (d) TNF- $\alpha$, (e) IL-6, and (f) IL-12 cytokines from cell culture supernatants after 24 h of incubation in the different conditions. Data are presented as the mean \pm standard error of the mean $(n=5)$ and were analyzed using one-way analysis of variance (ANOVA) and the Dunnett's post-hoc test $\left({ }^{*} \mathrm{p}<0.05,{ }^{* *} \mathrm{p}<0.01\right.$, compared to the untreated condition). 


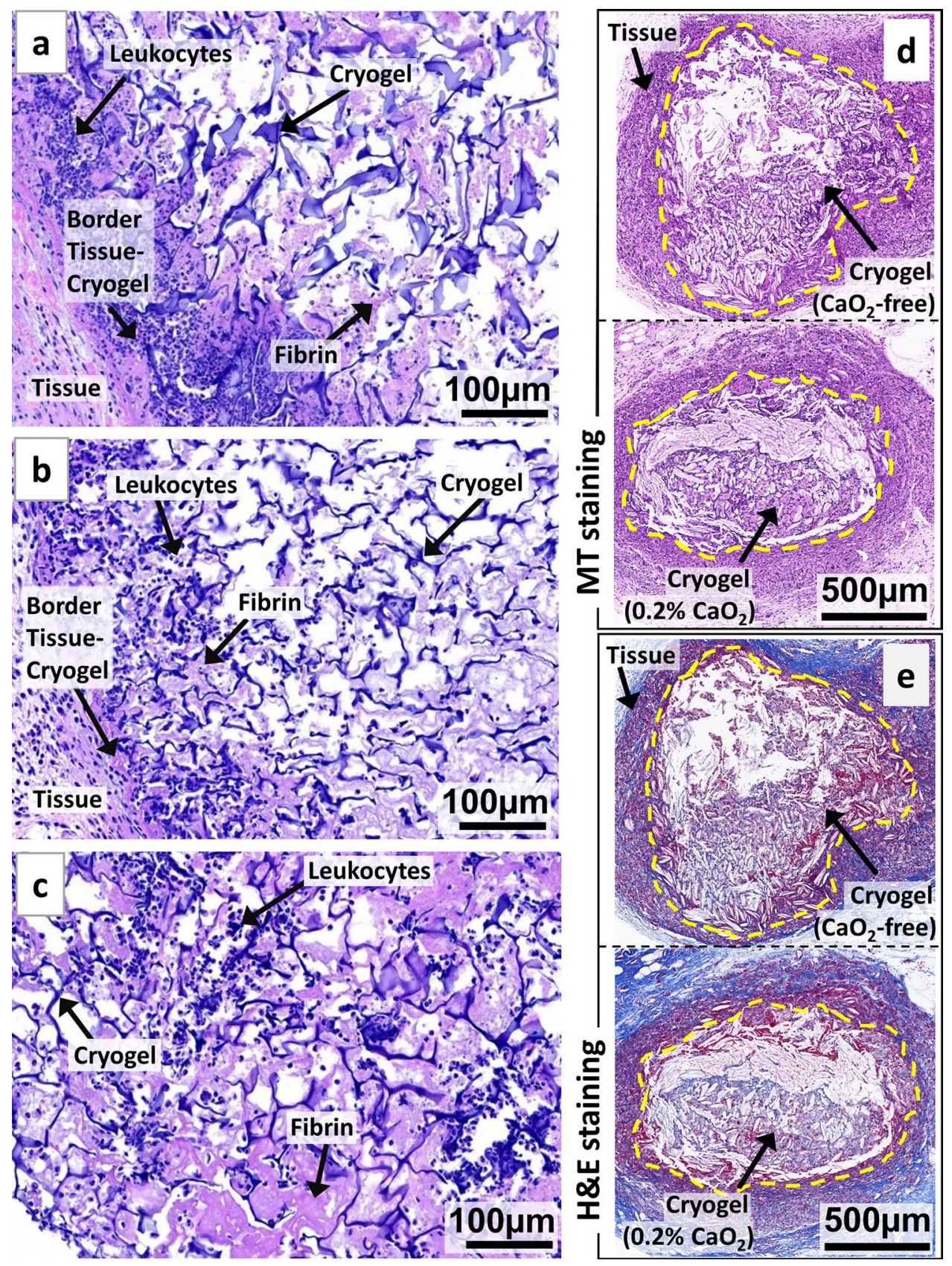

Figure 7. Antimicrobial microcomposite cryogels are biodegradable and elicit minimal host inflammatory responses. $\mathrm{H} \& \mathrm{E}$ staining of HAGM cryogel scaffold sections explanted 4 days following subcutaneous injections in the dorsal flanks of C57BL/6 mice: (a) CP-free cryogel $\left(0 \% \mathrm{CaO}_{2}\right)$, (b) CP-containing $\left(0.1 \% \mathrm{CaO}_{2}\right)$ cryogel, and (c) CP-containing $\left(0.1 \% \mathrm{CaO}_{2}\right)$ cryogel contaminated with P. aeruginosa. $\mathrm{H} \& \mathrm{E}$ staining highlights the macroporous polymeric network of cryogels (interconnected dark blue fibers), infiltrated leukocytes (dark blue dots), fibrin formation (purple), and surrounding tissues (cryogel-free). Masson's trichrome (MT) (d) and $\mathrm{H} \& \mathrm{E}$ (e) staining of square-shaped implants explanted 2 months following subcutaneous injections in the dorsal flanks of C57BL/6 mice: CP-free $\left(0 \% \mathrm{CaO}_{2}\right)$ and CP-containing $\left(0.2 \% \mathrm{CaO}_{2}\right)$ cryogels (dimensions: $4 \mathrm{~mm} \times 4 \mathrm{~mm} \times 1 \mathrm{~mm}$ ). The yellow doted lines indicate the boundary between the cryogel and the host tissue. Images are representative of $n=5$ samples per condition.

concentrations of IL-6, IL-12 and TNF- $\alpha$ (Fig. $6 \mathrm{~d}-\mathrm{f}$ ) further demonstrate that all cryogels induced minimal immunogenicity.

In vivo immunogenic response and biodegradation of antimicrobial cryogels. Finally, we examined the immunological response of the antimicrobial cryogels in a mouse model. CP-free cryogels, CP-containing $\left(0.1 \% \mathrm{CaO}_{2}\right)$ cryogels, and $\mathrm{CP}$-containing $\left(0.1 \% \mathrm{CaO}_{2}\right)$ cryogels contaminated with $P$. aeruginosa, were 
subcutaneously injected into the backs of C57BL/6 mice. Next, the cryogels were explanted on day 4 and subsequently stained with hematoxylin and eosin ( $\mathrm{H} \& \mathrm{E})$ for histological analysis (Fig. 7a-c). We assessed the cellular infiltration into cryogels as well as their integration within the surrounding tissues. Overall, across the three groups tested, cryogels were surrounded by a thin capsule of fibrin and induced a minimal infiltration of leukocytes (e.g., neutrophils and macrophages). It is worth noting that fibrin production and leukocyte infiltration were slightly more observable for the bacteria-contaminated antimicrobial cryogels. Consistent with their high degree of cytocompatibility and minimal in vitro DC activation, these microcomposite antimicrobial cryogels indicated minimal host inflammatory responses in mice.

The biodegradation of biomaterials is an essential criterion when designing implantable medical devices. Therefore, we have assessed the extent of cryogel degradation upon subcutaneous injection in mice. CP-free $(0 \%$ $\left.\mathrm{CaO}_{2}\right)$ and $\mathrm{CP}$-containing $\left(0.2 \% \mathrm{CaO}_{2}\right)$ cryogels were tested and after a 2-month implantation, the explanted cryogels displayed signs of degradation (Fig. 7). Compared to their initial dimensions $(4 \mathrm{~mm} \times 4 \mathrm{~mm} \times 1 \mathrm{~mm})$, both types of cryogels were clearly smaller, especially for CP-containing cryogels (Fig. $7 \mathrm{~d}-\mathrm{e}$ ). This set of data suggests that the incorporation of $\mathrm{CP}$ into cryogels may promote biodegradation.

\section{Discussion}

Three-dimensional scaffolds that exhibit a highly porous architecture could be very useful for several biomedical applications especially in tissue engineering ${ }^{1,75}$. Macroporous cryogels have been made from a variety of natural polymers meant to recapitulate the composition and structural properties of the $\mathrm{ECM}^{1,37,44}$. For example, by varying the polymerization temperature and cooling rate ${ }^{87}$, the mechanical properties of cryogels could be tuned to match those of the native tissues. Similarly, injectable cryogels with improved mechanical properties compared to their hydrogel counterparts can be fabricated ${ }^{87,88}$. However, microbial infections remain a major challenge associated with scaffolds and biomedical implants. Specifically, in clinical orthopedics, complications related to pathogenic bacterial colonization represent a major barrier to tissue repair and healing ${ }^{89}$. Although various approaches have been explored to confer hydrogels with antimicrobial properties, they have been associated with a number of limitations, including cytotoxicity and poor tissue integration ${ }^{90-92}$. Here, we report the fabrication of multifunctional cryogels (i.e., needle-injectable, biodegradable, and with antimicrobial activity) that could improve current strategies for developing scaffolds for tissue engineering.

In our study, we incorporated CP that imparts antibacterial activity to the cryogel scaffolds. The hydrolysis of $\mathrm{CP}$ leads to the formation of calcium hydroxide and hydrogen peroxide. Although calcium hydroxide is used as an antimicrobial medication in dentistry ${ }^{83}$, it did not appear to drive the antibacterial activity of CP-containing cryogels at the concentration reported in our study (Fig. 3b). The presence of catalase (i.e., an enzyme that degrades hydrogen peroxide) resulted in the total loss of the antibacterial activity of $\mathrm{CP}$, pointing to the production of hydrogen peroxide as the primary driver of the observed antibacterial effects. Conversely, in medical settings, hydrogen peroxide is used as an antiseptic solution for wound disinfection and irrigation at concentrations as high as $30 \%$. Lower concentrations of 3-6\% also have bactericidal action ${ }^{93}$. Unlike cryogels that are loaded with antibiotics ${ }^{94,95}$, our cryogels based on hydrogen peroxide-mediated bacterial inhibition have a minimal risk of eliciting resistance ${ }^{96}$. Although bacteria possess multiple antioxidant defenses to fight reactive oxygen species ${ }^{86}$ our CP-containing cryogels can release $>450 \mu \mathrm{mol}$ of hydrogen peroxide producing hydroxyl radicals that cannot be detoxified by bacterial enzymes ${ }^{86,96,97}$.

Previously, scaffolds loaded with CP have been used for oxygen release ${ }^{98}$. Converting hydrogen peroxide from $\mathrm{CP}$ to water and oxygen can be useful for tissue engineering applications ${ }^{99,100}$. However, the concentration of CP has to be finely tuned to prevent cytotoxic side effects. In our study, CP-containing cryogels producing hydrogen peroxide were sufficient to inhibit bacterial growth, while there was minimal to no observable toxicity to mammalian cells. We showed that NIH/3T3 cells cultured with CP-containing cryogels exhibited high cell viability (Fig. 5). Similarly, these cryogels seemed unlikely to induce an inflammatory response ${ }^{101,102}$. We observed that these cryogels do not activate or trigger the secretion of proinflammatory cytokines when cultured with primary DCs (i.e., BMDCs). Similarly, in the in vivo setting, the cryogels induced minimal inflammatory reactions even when purposely contaminated with bacteria prior to implantation. This result reaffirms our hypothesis that CPcontaining cryogels can provide strong antimicrobial activity and prevent bacterial colonization. In addition to its antimicrobial activity, hydrogen peroxide has been reported to have antiviral and antifungal properties ${ }^{81,82}$. We hypothesize that CP-containing cryogels could potentially have some biocidal actions against other microorganisms (e.g., virus, yeasts, molds) and further studies are needed. Another advantage of this platform is that the injectable scaffolds are preformed, enabling them to recover their shape at the site of injection and thus eliminating the need for in situ gelation. Furthermore, CP-containing cryogels exhibited signs of biodegradation after 2 months when subcutaneously injected in mice. The degradation may be the result of enzymatic hydrolysis and oxidation ${ }^{88,89}$. These unique characteristics make these microcomposite cryogels very attractive for a wide range of biomedical applications, including designing scaffolds for tissue engineering and regenerative medicine.

Multiple CP-containing cryogels were formulated for this study and the resulting concentration of microparticles was relatively low. While for the purpose of our study (i.e., to prevent implant-associated infections), the transient antimicrobial activity of our cryogels is acceptable, a more prolonged biocidal action may be required for other applications such as wound healing. However, a finely tuned balance needs to be achieved between hydrogen peroxide generation and its possible cytotoxicity on mammalian cells. To that end, adjusting CP hydrolysis, and ultimately hydrogen peroxide production within its biocompatible range, is necessary. Using other metal peroxides such as magnesium peroxide could potentially provide a more sustained yet low level of hydrogen peroxide release. Although it may be not needed due to the potential biocidal action of hydrogen peroxide across several microorganisms, another potential limitation of these CP-containing cryogels is that they might not be able to undergo autoclave sterilization, as previously reported by our group ${ }^{88}$. It remains to be 
studied whether the highly dense and interconnected polymers in cryogels can provide sufficient protection for $\mathrm{CP}$ hydrolysis during autoclave treatment or whether alternative sterilization techniques could be used. Similarly, when combining CP-containing cryogels with other drugs or proteins to be released from the cryogels, possible interactions or damage resulting from the presence of hydrogen peroxide might need to be taken into consideration. Finally, the needle-injectable antibacterial cryogels reported here were $16 \mathrm{~mm}^{3}$. However, for some tissue engineering applications, it might be necessary to deliver larger cryogel constructs that are above the currently reported volume. In such cases, it might be best to use catheters instead of standard needle-injections.

\section{Conclusion}

In this work, we engineered injectable microcomposite cryogels with antimicrobial properties. The cryogels with an interconnected network of large pores $(10-100 \mu \mathrm{m})$ could be delivered using minimally invasive approaches (i.e., injected through hypodermic $16 \mathrm{G}$ needles) without any structural alteration. The incorporation of CP at low concentrations within the cryogels inhibited the growth of multiple pathogenic bacterial strains that are commonly associated with implant failures. The antibacterial activity seemed to be primarily driven by the production of hydrogen peroxide, a byproduct of CP degradation found in the cryogels. While hydrogen peroxide retarded or prevented bacterial growth, it had little to no effect on NIH/3T3 cell viability, and these cryogels did not seem to trigger detectable BMDC activation. Similarly, antimicrobial cryogels did not induce an inflammatory response when tested in mice even when purposely contaminated with pathogenic bacteria prior to subcutaneous injections. Furthermore, cryogels indicated clear signs of degradation in vivo. Collectively, these results indicate that needle-injectable and biodegradable CP-containing cryogels exhibit antimicrobial activity that holds great promise for a wide variety of biomedical applications, particularly when designing tissue engineering scaffolds.

\section{Materials and Methods}

Materials. HA (molecular weight $\sim 330 \mathrm{kDa}$ ) was obtained from Blooming, China. Phosphate-buffered saline (PBS), dimethylformamide, glycidyl methacrylate, triethylamine, acetone, tetramethylethylenediamine (TEMED), ammonium persulfate (APS), Alizarin Red S (ARS) stain, a fluorometric hydrogen peroxide assay kit (MAK 165), bovine catalase (2000-5000 units/mg of protein), Dulbecco's modified Eagle's medium (DMEM), fetal bovine serum (FBS), 4',6-diamidino-2-phenylindole (DAPI), and Triton X-100 were purchased from Sigma-Aldrich. Tryptic soy broth (TSB) was purchased from MP Biomedicals. Agar was purchased from Fisher Bioreagents. GGGGRGDSP (G4RGDSP) was synthesized by Peptide 2.0. Penicillin, streptomycin, and RPMI 1640 were purchased from Fisher Scientific. Far-red fixable live/dead stain (Alexa Fluor $647 \mathrm{~nm}$ ) was purchased from GeneCopoeia. Alexa Fluor 488-phalloidin was obtained from Cell Signaling Technology. The BioLegend IL-6 ELISA max deluxe set (431304), BioLegend TNF-alpha ELISA max deluxe set (430904), and BioLegend IL-12 (p70) ELISA max deluxe set were used. Fluorescent antibodies for flow cytometry (specific for CD86, CD11c and MHCII) were procured from BioLegend.

Chemical modification and characterization of HA. Methacrylate groups were added to HA to yield the HA-glycidyl methacrylate (HAGM) conjugate as per the procedure mentioned by Rezaeeyazdi et al. ${ }^{103}$, which allows cross-linking. Quantification of the degree of methacrylation was performed by ${ }^{1} \mathrm{H}$ NMR analysis using a Varian Inova-500 NMR spectrometer. The degree of methacrylation was calculated according to a method previously described ${ }^{55}$. The HAGM macromonomer was found to have a degree of methacrylation of approximatively 20\% (Supplementary Fig. 5).

Fabrication and characterization of antimicrobial microcomposite cryogels. The HAGM 4\% $(\mathrm{w} / \mathrm{v})$ macromonomer was dissolved in deionized water, mixed with an appropriate amount of CP, and subjected to free radical polymerization induced by $0.5 \%$ (w/v) TEMED and $0.25 \%(\mathrm{w} / \mathrm{v})$ APS. This prepolymer mix was distributed into precooled Teflon molds. Polymerization was then allowed to complete at a subzero temperature, i.e., $-20^{\circ} \mathrm{C}$, for $17 \mathrm{~h}^{33}$. After completion of the polymerization, the gels were brought to room temperature (RT) to remove ice crystals and washed with deionized water.

The swelling ratio was determined using a standard gravimetric procedure. To calculate the swelling ratio of each sample, cryogel samples $8 \mathrm{~mm}$ in diameter and $6 \mathrm{~mm}$ in height $(\mathrm{n}=4)$ were prepared and immersed in PBS at $\mathrm{pH} 7.4$ and $37^{\circ} \mathrm{C}$. The equilibrium mass swelling ratio $\left(\mathrm{Q}_{\mathrm{M}}\right)$ was calculated by the equation $\mathrm{Q}_{\mathrm{M}}=\mathrm{ms} / \mathrm{md}$, where $\mathrm{ms}$ and $\mathrm{md}$ were the fully swollen gel and freeze-dried gel weights, respectively. The Young's modulus was determined using an Instron testing system (Instron 5944). Cylindrical cryogels (6 mm in diameter, $8 \mathrm{~mm}$ in height) were deformed between two parallel plates with a strain rate of $10 \%$ per minute for multiple cycles. To measure the degree of interconnectivity, disc-shaped cryogels (13 $\mathrm{mm}$ in diameter, $1 \mathrm{~mm}$ in height) were fabricated. The interconnected void volume was calculated as the ratio of weight of water wicked from the gels by a Kimwipe to the wet weight of fully soaked cryogel disks ${ }^{33}$.

Cryogel injectability. The ability of cryogels to pass through a conventional-gauge needle and then regain their original shapes was checked by injecting the cryogel through a hypodermic needle. First, square-shaped HAGM cryogels (dimensions: $4 \mathrm{~mm} \times 4 \mathrm{~mm} \times 1 \mathrm{~mm}$ ) were suspended in $0.2 \mathrm{ml}$ of PBS and syringe-injected through a $16 \mathrm{G}$ needle. ARS, an anthraquinone dye, has been widely used as a sensitive technique for the semi quantification of calcium deposits ${ }^{63}$. A $1 \%$ ARS solution was prepared in deionized water, and the $\mathrm{pH}$ was adjusted to 4.2. Fresh solution was used for the assay. Cryogel samples were dipped in the ARS solution for $20 \mathrm{~min}$ and then washed with deionized water multiple times until there was no color in the surrounding liquid. 
Microstructural imaging. SEM imaging, control $\left(0 \% \mathrm{CaO}_{2}\right.$ in $\left.4 \% \mathrm{HAGM}\right)$ and antimicrobial (supplemented with $0.1 \%$ or $0.2 \% \mathrm{CaO}_{2}$ ) square-shaped cryogel samples (dimensions: $4 \mathrm{~mm} \times 4 \mathrm{~mm} \times 1 \mathrm{~mm}$ ) were fabricated, lyophilized, and sputter-coated with platinum to a thickness of $5 \mathrm{~nm}$. Then, the cryogels were observed under a JEOL S 4800 microscope operating at a $15 \mathrm{kV}$ voltage and $20 \mu \mathrm{A}$ current. The average pore size of the cryogels was calculated by averaging the diameters of the pores as observed by SEM.

Evaluating hydrogen peroxide release from cryogels. Hydrogen peroxide release was measured using a fluorometric hydrogen peroxide assay kit (Sigma Aldrich, MAK 165). First, square-shaped cryogel samples $(4 \mathrm{~mm} \times 4 \mathrm{~mm} \times 1 \mathrm{~mm})$ containing $0 \%, 0.1 \%$ and $0.2 \% \mathrm{CaO}_{2}(\mathrm{n}=5)$ were placed in $200 \mu \mathrm{l}$ of PBS per cryogel in a 24 -well plate at room temperature and $200 \mathrm{rpm}$. At $15 \mathrm{~min}, 1 \mathrm{~h}, 2 \mathrm{~h}, 3 \mathrm{~h}, 4 \mathrm{~h}$ and $5 \mathrm{~h}$, the cryogels were transferred to fresh PBS in a new well, $50 \mu \mathrm{l}$ of the sample was removed, and the amount of $\mathrm{H}_{2} \mathrm{O}_{2}$ released was measured fluorometrically. Assays were performed according to the manufacturer's instructions. The readings were normalized with the readings observed with control $\left(0 \% \mathrm{CaO}_{2}\right)$ cryogels and were recorded until the fluorescence vanished.

Assessment of antibacterial activity. Effects of calcium hydroxide, CP, and CP neutralized with catalase were tested. To evaluate the effect of individual compositions, $1 \times 10^{5}$ MRSA cells from overnight-grown cultures were exposed to $0.1 \%$ calcium hydroxide or CP, equivalent to the amount loaded in cryogel samples. Additionally, bovine catalase (200-500 units) was used along with CP. The response in terms of cell density (i.e., absorbance at $562 \mathrm{~nm}$ ) was monitored for $24 \mathrm{~h}$ and the average values were plotted $(\mathrm{n}=5)$.

Assessment of antibacterial action of CP-containing cryogels. MRSA (ATCC 43300), P. aeruginosa (ATCC 27853), multi-drug-resistant E. coli (ATCC 25922) and Streptococcus pyogenes (ATCC 12384) were used as test pathogens. Overnight-grown bacterial cultures were used in these experiments. Cell density was adjusted by means of absorbance to obtain $1 \times 10^{6}$ cells $/ \mathrm{ml}$. Cylindrical cryogels $(6 \mathrm{~mm}$ in diameter, $8 \mathrm{~mm}$ in height) with varying concentrations of $\mathrm{CP}(0 \%, 0.1 \%$, and $0.2 \%)$ were sanitized, washed, partially dried over sterile gauze and inoculated with $5 \times 10^{4}$ cells with TSB media. After $6 \mathrm{~h}$ of incubation at $37^{\circ} \mathrm{C}$ and $5 \% \mathrm{CO}_{2}$, the cryogels were flushed with $350 \mu \mathrm{l}$ of sterile PBS and subjected to CFU determination using $10 \mu \mathrm{l}$ from serial dilutions. The method has been adapted and suitably modified from ${ }^{104}$. For SEM imaging, samples were fixed with $4 \%$ paraformaldehyde and dehydrated serially in 20, 40, 60, 80 and 100\% ethanol for 15 min each, followed by critical point drying (samdri-PVT-3D). Platinum-coated $(5 \mathrm{~nm})$ samples were observed with a JEOL S 4800 scanning electron microscope as mentioned earlier.

To confirm the antibacterial potential of cryogels after lyophilization as well as injection, cryogel samples (dimensions: $4 \mathrm{~mm} \times 4 \mathrm{~mm} \times 1 \mathrm{~mm}$ ) with $0.2 \% \mathrm{CP}$ were fabricated and lyophilized immediately. They were briefly sanitized, washed, partially dried over sterile gauze and inoculated with 1000 cells of bacterial pathogen in TSB. Experiments were performed with MRSA and P. aeruginosa. After $4 \mathrm{~h}$ of incubation, the cryogels were flushed with sterile PBS, and the PBS used for washing was subjected to CFU determination (Supplementary Figs. 6 and 7).

Assessment of biocompatibility. Cryogels with $0 \%, 0.1 \%$ and $0.2 \%$ CP were fabricated as mentioned in previous sections. They were supplemented with $0.8 \% \mathrm{w} / \mathrm{w}$ ACRL-PEG-G4RGDSP to promote mammalian cell adhesion. The cryogels were briefly sanitized in $70 \%$ ethanol, washed, and partially dried over sterile gauze. The collapsed cryogels were placed in a multiwell plate. A total of $50 \mathrm{k} 3 \mathrm{~T} 3$ cells (NIH/3T3, CRL-1658, ATCC) suspended in $10 \mu \mathrm{l}$ of DMEM supplemented with $10 \%$ FBS and $1 \%$ penicillin-streptomycin were uniformly distributed onto each cryogel piece. They were allowed to adhere to the cryogel for $2 \mathrm{~h}$. Then, $200 \mu \mathrm{l}$ of culture medium was added to the wells. After $24 \mathrm{~h}$ of incubation, the cryogels were recovered, stained with ViaQuantTM Far-red according to the manufacturer's instructions, and fixed with $4 \%$ paraformaldehyde in PBS for $30 \mathrm{~min}$. The cells were permeabilized with $0.1 \%$ Triton X-100 for $5 \mathrm{~min}$ in PBS and stained with Alexa Fluor 488-phalloidin and DAPI according to the manufacturer's protocol. The cryogels were observed under a Leica TCS SP5 X WLL confocal microscope, and images were recorded. Four representative samples were used to calculate the $\%$ viability.

Assessment of in vitro immune response with dendritic cells (DCs). For this study, BMDCs were obtained as previously described ${ }^{105}$. A 24 -well plate was seeded with $200 \times 10^{3}$ cells per well in RPMI 1640 medium supplemented with FBS. Cryogels with $0 \%, 0.1 \%$, and $0.2 \% \mathrm{CP}$ of size $4 \mathrm{~mm} \times 4 \mathrm{~mm} \times 1 \mathrm{~mm}$ were used. They were briefly sanitized in $70 \%$ ethanol, washed, partially, and dried over sterile gauze, followed by $24 \mathrm{~h}$ of coincubation with DCs.

The supernatant was checked for the presence of secreted cytokines by ELISA. The supernatants were suitably diluted for IL-6, TNF- $\alpha$, and IL-12, and assays were performed according to the manufacturer's instructions. DCs were recovered from the well plate as well as from within the cryogels with the help of a cell scraper and were fixed with $4 \%$ paraformaldehyde treatment. The activation of DCs was assessed with flow cytometry (BD FACS Calibur DxP), and the expression levels of CD11c, CD86, and MHCII were quantified. Expression levels were interpreted based on BMDCs cultured in media alone as a negative control and BMDCs incubated in media with $100 \mathrm{ng} / \mathrm{mL}$ LPS as a positive control.

Assessment of in vivo response. The in vivo response and tissue integration upon subcutaneous injection of CP-containing cryogels were assessed. First, cryogels (dimensions: $4 \mathrm{~mm} \times 4 \mathrm{~mm} \times 1 \mathrm{~mm}$ ) were fabricated with $0 \%$ and $0.1 \% \mathrm{CP}$. Another set of samples consisted of CP-containing cryogels $\left(0.1 \% \mathrm{CaO}_{2}\right)$ challenged with 
$2 \times 10^{3} \mathrm{P}$. aeruginosa cells. The cryogels were briefly sanitized with $70 \%$ ethanol and washed with sterile PBS. Cryogels suspended in sterile PBS $(0.2 \mathrm{~mL})$ were syringe-injected through $16 \mathrm{G}$ needles in both dorsal flanks of 8-weeks old female C57BL/6J mice ( $n=5 /$ condition, The Jackson Laboratory, Bar Harbor, ME, USA) ${ }^{105}$. To observe cellular infiltration and signs of tissue integration, mice were sacrificed at day 4 , and cryogels explanted to perform histological analysis. Cryogels were then fixed in $4 \%$ paraformaldehyde (PFA), embedded in paraffin, and then sectioned ( $5 \mu \mathrm{m}$ thick). The slices were first stained with H\&E or MT and subsequently imaged (Mass Histology Services, Worcester, MA, USA).

Assessment of in vivo biodegradation. CP-free $\left(0 \% \mathrm{CaO}_{2}\right)$ and $0.2 \% \mathrm{CaO}_{2}$ cryogels (dimensions: $4 \mathrm{~mm} \times 4 \mathrm{~mm} \times 1 \mathrm{~mm}$ ) were assessed for their capacity to degrade in the body. Cryogels suspended in sterile PBS $(0.2 \mathrm{~mL})$ were syringe-injected through $16 \mathrm{G}$ needles in both dorsal flanks of 12 -weeks old female C57BL/6J mice ( $n=5 /$ condition, The Jackson Laboratory, Bar Harbor, ME, USA). Each mouse received both cryogel types, one on each flank. After 2 months, mice were euthanized and the cryogels explanted with the surrounding tissues to perform histological analysis. Cryogels were then fixed in $4 \%$ PFA, embedded in paraffin, and then sectioned ( $5 \mu \mathrm{m}$ thick). The slices were first stained with H\&E or MT and subsequently imaged (iHisto, Woburn, MA, USA). Animal work was performed under an approved protocol by the Northeastern University Standing Committee on Animals in compliance with the National Institutes of Health guidelines.

Received: 1 January 2020; Accepted: 1 October 2020

Published online: 27 October 2020

\section{References}

1. O’Brien, F. J. Biomaterials \& scaffolds for tissue engineering. Mater. Today 14, 88-95. https://doi.org/10.1016/s1369 -7021(11)70058-x (2011).

2. Willerth, S. M. \& Sakiyama-Elbert, S. E. Combining stem cells and biomaterial scaffolds for constructing tissues and cell delivery. StemJournal 1, 1-25. https://doi.org/10.3233/stj-180001 (2019).

3. Xiao, Y., Ahadian, S. \& Radisic, M. Biochemical and biophysical cues in matrix design for chronic and diabetic wound treatment. Tissue Eng. Part B Rev. 23, 9-26. https://doi.org/10.1089/ten.TEB.2016.0200 (2017).

4. Abudula, T. et al. Oxygen-releasing antibacterial nanofibrous scaffolds for tissue engineering applications. Polymers (Basel) 12 , 1233. https://doi.org/10.3390/polym12061233 (2020).

5. Amirsadeghi, A. et al. Vascularization strategies for skin tissue engineering. Biomater. Sci. 8, 4073-4094. https://doi.org/10.1039/ dobm00266f (2020).

6. Barua, S., Chattopadhyay, P., Aidew, L., Buragohain, A. K. \& Karak, N. Infection-resistant hyperbranched epoxy nanocomposite as a scaffold for skin tissue regeneration. Polym. Int. 64, 303-311. https://doi.org/10.1002/pi.4790 (2015).

7. Feinberg, A. W. Engineered tissue grafts: opportunities and challenges in regenerative medicine. Wiley Interdiscip. Rev. Syst. Biol. Med. 4, 207-220. https://doi.org/10.1002/wsbm.164 (2012).

8. Naderi, H., Matin, M. M. \& Bahrami, A. R. Review paper: critical issues in tissue engineering: biomaterials, cell sources, angiogenesis, and drug delivery systems. J. Biomater. Appl. 26, 383-417. https://doi.org/10.1177/0885328211408946 (2011).

9. Memic, A. et al. Latest progress in electrospun nanofibers for wound healing applications. ACS Appl. Bio Mater. 2, 952-969. https://doi.org/10.1021/acsabm.8b00637 (2019).

10. Russo, T. et al. Systematic analysis of injectable materials and 3d rapid prototyped magnetic scaffolds: from CNS applications to soft and hard tissue repair/regeneration. Proc. Eng. 59, 233-239. https://doi.org/10.1016/j.proeng.2013.05.116 (2013).

11. Bencherif, S. A. et al. Influence of cross-linker chemistry on release kinetics of PEG-co-PGA hydrogels. J. Biomed. Mater. Res. A 90, 142-153. https://doi.org/10.1002/jbm.a.32069 (2009).

12. Memic, A. et al. Nanofibrous silver-coated polymeric scaffolds with tunable electrical properties. Nanomaterials (Basel) 7,63 . https://doi.org/10.3390/nano7030063 (2017).

13. Abudula, T. et al. The effect of poly (glycerol sebacate) incorporation within hybrid chitin-lignin sol-gel nanofibrous scaffolds. Materials (Basel) 11, 451. https://doi.org/10.3390/ma11030451 (2018).

14. Chhatri, A. et al. Cryogenic fabrication of savlon loaded macroporous blends of alginate and polyvinyl alcohol (PVA). Swelling, deswelling and antibacterial behaviors. Carbohydr. Polym. 83, 876-882. https://doi.org/10.1016/j.carbpol.2010.08.077 (2011).

15. Caló, E. \& Khutoryanskiy, V. V. Biomedical applications of hydrogels: a review of patents and commercial products. Eur. Polym. J. 65, 252-267. https://doi.org/10.1016/j.eurpolymj.2014.11.024 (2015).

16. Veiga, A. S. \& Schneider, J. P. Antimicrobial hydrogels for the treatment of infection. Biopolymers 100, 637-644. https://doi. org/10.1002/bip.22412 (2013).

17. Priya, S. G. et al. Bilayer cryogel wound dressing and skin regeneration grafts for the treatment of acute skin wounds. ACS Appl. Mater. Interfaces 8, 15145-15159. https://doi.org/10.1021/acsami.6b04711 (2016).

18. Kim, J., Bencherif, S. A., Li, W. A. \& Mooney, D. J. Cell-friendly inverse opal-like hydrogels for a spatially separated co-culture system. Macromol. Rapid Commun. 35, 1578-1586. https://doi.org/10.1002/marc.201400278 (2014).

19. Gsib, O. et al. Evaluation of fibrin-based interpenetrating polymer networks as potential biomaterials for tissue engineering. Nanomaterials (Basel) 7, 436. https://doi.org/10.3390/nano7120436 (2017).

20. Gsib, O., Egles, C. \& Bencherif, S. A. Fibrin-an underrated biopolymer for skin tissue engineering. J. Mol. Biol. Biotechnol. 2, 1-4 (2017).

21. Bencherif, S. A. et al. End-group effects on the properties of PEG-co-PGA hydrogels. Acta Biomater. 5, 1872-1883. https://doi. org/10.1016/j.actbio.2009.02.030 (2009).

22. Gsib, O. et al. FibriDerm: interpenetrated Fibrin scaffolds for the construction of Human Skin Equivalents for full thickness burns. IRBM 39, 103-108. https://doi.org/10.1016/j.irbm.2017.10.006 (2018).

23. Joshi Navare, K. et al. In Racing for the Surface: Pathogenesis of Implant Infection and Advanced Antimicrobial Strategies (eds Li, B. et al.) 511-542 (Springer International Publishing, 2020).

24. Bencherif, S. A. et al. Influence of cross-linker chemistry on release kinetics of PEG-co-PGA hydrogels. J. Biomed. Mater. Res. Part A 90, 142-153. https://doi.org/10.1002/jbm.a.32069 (2009).

25. Prata, J. E., Barth, T. A., Bencherif, S. A. \& Washburn, N. R. Complex fluids based on methacrylated hyaluronic acid. Biomacromol 11, 769-775. https://doi.org/10.1021/bm901373x (2010).

26. Oyen, M. L. Mechanical characterisation of hydrogel materials. Int. Mater. Rev. 59, 44-59. https://doi.org/10.1179/1743280413 y.0000000022 (2013). 
27. Gloria, A., Borzacchiello, A., Causa, F. \& Ambrosio, L. Rheological characterization of hyaluronic acid derivatives as injectable materials toward nucleus pulposus regeneration. J. Biomater. Appl. 26, 745-759. https://doi.org/10.1177/0885328210387174 (2012).

28. Li, J. \& Mooney, D. J. Designing hydrogels for controlled drug delivery. Nat. Rev. Mater. https://doi.org/10.1038/natrevmats .2016.71 (2016).

29. Zhu, J. \& Marchant, R. E. Design properties of hydrogel tissue-engineering scaffolds. Expert Rev. Med. Devices 8, 607-626. https ://doi.org/10.1586/erd.11.27 (2011).

30. Baier Leach, J., Bivens, K. A., Patrick, C. W. Jr. \& Schmidt, C. E. Photocrosslinked hyaluronic acid hydrogels: natural, biodegradable tissue engineering scaffolds. Biotechnol. Bioeng. 82, 578-589. https://doi.org/10.1002/bit.10605 (2003).

31. Rogers, Z. J., Zeevi, M. P., Koppes, R. \& Bencherif, S. A. Electroconductive hydrogels for tissue engineering: current status and future perspectives. Bioelectricity https://doi.org/10.1089/bioe.2020.0025 (2020).

32. Bahram, M., Mohseni, N. \& Moghtader, M. An introduction to hydrogels and some recent applications. In Emerging Concepts in Analysis and Applications of Hydrogels (ed Majee, S. B.), doi: 10.5772/64301 (IntechOpen Publishing, 2016).

33. Bencherif, S. A. et al. Injectable preformed scaffolds with shape-memory properties. Proc. Natl. Acad. Sci. U. S. A. 109, 1959019595. https://doi.org/10.1073/pnas.1211516109 (2012).

34. Jungst, T., Smolan, W., Schacht, K., Scheibel, T. \& Groll, J. Strategies and molecular design criteria for 3D printable hydrogels. Chem. Rev. 116, 1496-1539. https://doi.org/10.1021/acs.chemrev.5b00303 (2016).

35. Guvendiren, M., Lu, H. D. \& Burdick, J. A. Shear-thinning hydrogels for biomedical applications. Soft Matter 8, 260-272. https ://doi.org/10.1039/c1sm06513k (2012).

36. Loebel, C., Rodell, C. B., Chen, M. H. \& Burdick, J. A. Shear-thinning and self-healing hydrogels as injectable therapeutics and for 3D-printing. Nat. Protoc. 12, 1521-1541. https://doi.org/10.1038/nprot.2017.053 (2017).

37. Eggermont, L. J., Rogers, Z. J., Colombani, T., Memic, A. \& Bencherif, S. A. Injectable cryogels for biomedical applications. Trends Biotechnol. https://doi.org/10.1016/j.tibtech.2019.09.008 (2019).

38. Rogers, Z. J. \& Bencherif, S. A. Cryogelation and cryogels. Gels https://doi.org/10.3390/gels5040046 (2019).

39. Memic, A. et al. Effect of polymer concentration on autoclaved cryogel properties. Macromol. Mater. Eng. https://doi.org/10.1002/ mame.201900824 (2020).

40. Bencherif, S. A., Braschler, T. M. \& Renaud, P. Advances in the design of macroporous polymer scaffolds for potential applications in dentistry. J. Periodontal Implant Sci. 43, 251-261. https://doi.org/10.5051/jpis.2013.43.6.251 (2013).

41. Han, M. E. et al. Extracellular matrix-based cryogels for cartilage tissue engineering. Int. J. Biol. Macromol. 93, 1410-1419. https ://doi.org/10.1016/j.ijbiomac.2016.05.024 (2016).

42. Shih, T. Y. et al. Injectable, tough alginate cryogels as cancer vaccines. Adv. Healthc. Mater. 7, e1701469. https://doi.org/10.1002/ adhm.201701469 (2018).

43. Kennedy, S. et al. Rapid and extensive collapse from electrically responsive macroporous hydrogels. Adv. Healthc. Mater. 3, 500-507. https://doi.org/10.1002/adhm.201300260 (2014).

44. Memic, A. et al. Latest advances in cryogel technology for biomedical applications. Adv. Ther. https://doi.org/10.1002/adtp.20180 0114 (2019).

45. Beduer, A. et al. A compressible scaffold for minimally invasive delivery of large intact neuronal networks. Adv. Healthc. Mater. 4, 301-312. https://doi.org/10.1002/adhm.201400250 (2015).

46. Say, R. et al. Novel protein photocrosslinking and cryopolymerization method for cryogel-based antibacterial material synthesis. J. Appl. Polym. Sci. 125, 145-151. https://doi.org/10.1002/app.35376 (2012).

47. Demir, D. \& Bölgen, N. Synthesis and characterization of injectable chitosan cryogel microsphere scaffolds. Int. J. Polym. Mater. Polym. Biomater. 66, 686-696. https://doi.org/10.1080/00914037.2016.1255614 (2017).

48. Cheng, L. et al. Injectable shape-memorizing three-dimensional hyaluronic acid cryogels for skin sculpting and soft tissue reconstruction. Tissue Eng. Part A 23, 243-251. https://doi.org/10.1089/ten.TEA.2016.0263 (2017).

49. Liao, H. T., Shalumon, K. T., Chang, K. H., Sheu, C. \& Chen, J. P. Investigation of synergistic effects of inductive and conductive factors in gelatin-based cryogels for bone tissue engineering. J. Mater. Chem. B 4, 1827-1841. https://doi.org/10.1039/c5tb0 2496j (2016)

50. Jurga, M. et al. The performance of laminin-containing cryogel scaffolds in neural tissue regeneration. Biomaterials 32, 34233434. https://doi.org/10.1016/j.biomaterials.2011.01.049 (2011)

51. Odabas, S. Collagen-carboxymethyl cellulose-tricalcium phosphate multi-lamellar cryogels for tissue engineering applications: production and characterization. J. Bioactive Compat. Polym. 31, 411-422. https://doi.org/10.1177/0883911515627472 (2016).

52. Kadakia, P. U., Jain, E., Hixon, K. R., Eberlin, C. T. \& Sell, S. A. Sonication induced silk fibroin cryogels for tissue engineering applications. Mater. Res. Express https://doi.org/10.1088/2053-1591/3/5/055401 (2016).

53. Bhat, S., Tripathi, A. \& Kumar, A. Supermacroprous chitosan-agarose-gelatin cryogels: in vitro characterization and in vivo assessment for cartilage tissue engineering. J. R. Soc. Interface 8, 540-554. https://doi.org/10.1098/rsif.2010.0455 (2011).

54. Demirci, S., Suner, S., Sahiner, M. \& Sahiner, N. Superporous hyaluronic acid cryogel composites embedding synthetic polyethyleneimine microgels and halloysite nanotubes as natural clay. Eur. Polym. J. 93, 775-784. https://doi.org/10.1016/j.eurpo lymj.2017.04.022 (2017).

55. Bencherif, S. A. et al. Influence of the degree of methacrylation on hyaluronic acid hydrogels properties. Biomaterials 29, 1739-1749. https://doi.org/10.1016/j.biomaterials.2007.11.047 (2008).

56. Collins, M. N. \& Birkinshaw, C. Hyaluronic acid based scaffolds for tissue engineering-a review. Carbohydr. Polym. 92, 12621279. https://doi.org/10.1016/j.carbpol.2012.10.028 (2013).

57. Hemshekhar, M. et al. Emerging roles of hyaluronic acid bioscaffolds in tissue engineering and regenerative medicine. Int. J. Biol. Macromol. 86, 917-928. https://doi.org/10.1016/j.ijbiomac.2016.02.032 (2016).

58. Xu, X., Jha, A. K., Harrington, D. A., Farach-Carson, M. C. \& Jia, X. Hyaluronic acid-based hydrogels: from a natural polysaccharide to complex networks. Soft Matter 8, 3280-3294. https://doi.org/10.1039/C2SM06463D (2012).

59. Li, P. et al. A polycationic antimicrobial and biocompatible hydrogel with microbe membrane suctioning ability. Nat. Mater. 10, 149-156. https://doi.org/10.1038/nmat2915 (2011).

60. Ansari, M. O., Gauthaman, K., Eissa, A., Bencherif, S. A. \& Memic, A. Graphene and graphene-based materials in biomedical applications. Curr. Med. Chem. https://doi.org/10.2174/0929867326666190705155854 (2019).

61. Romano, C. L. et al. Does an antibiotic-loaded hydrogel coating reduce early post-surgical infection after joint arthroplasty?. J. Bone Jt. Infect. 1, 34-41. https://doi.org/10.7150/jbji.15986 (2016).

62. Dai, T. et al. A Nanocomposite hydrogel with potent and broad-spectrum antibacterial activity. ACS Appl. Mater. Interfaces 10, 15163-15173. https://doi.org/10.1021/acsami.8b02527 (2018).

63. Wang, J. et al. Oxygen-generating nanofiber cell scaffolds with antimicrobial properties. ACS Appl. Mater. Interfaces 3, 67-73. https://doi.org/10.1021/am100862h (2011).

64. Kazemzadeh-Narbat, M. et al. Multilayered coating on titanium for controlled release of antimicrobial peptides for the prevention of implant-associated infections. Biomaterials 34, 5969-5977. https://doi.org/10.1016/j.biomaterials.2013.04.036 (2013).

65. Zhu, J., Li, F., Wang, X., Yu, J. \& Wu, D. Hyaluronic acid and polyethylene glycol hybrid hydrogel encapsulating nanogel with hemostasis and sustainable antibacterial property for wound healing. ACS Appl. Mater. Interfaces 10, 13304-13316. https://doi. org/10.1021/acsami.7b18927 (2018). 
66. Giano, M. C. et al. Injectable bioadhesive hydrogels with innate antibacterial properties. Nat. Commun. 5, 4095. https://doi. org/10.1038/ncomms5095 (2014).

67. Li, L. et al. Injectable Self-healing hydrogel with antimicrobial and antifouling properties. ACS Appl. Mater. Interfaces 9, 92219225. https://doi.org/10.1021/acsami.6b16192 (2017).

68. Cheng, H. et al. Mussel-inspired multifunctional hydrogel coating for prevention of infections and enhanced osteogenesis. ACS Appl. Mater. Interfaces 9, 11428-11439. https://doi.org/10.1021/acsami.6b16779 (2017).

69. Zou, X. et al. Preparation of a novel antibacterial chitosan-poly(ethylene glycol) cryogel/silver nanoparticles composites. J. Biomater. Sci. Polym. Ed 28, 1324-1337. https://doi.org/10.1080/09205063.2017.1321346 (2017).

70. Zhao, X., Guo, B., Wu, H., Liang, Y. \& Ma, P. X. Injectable antibacterial conductive nanocomposite cryogels with rapid shape recovery for noncompressible hemorrhage and wound healing. Nat. Commun. 9, 2784. https://doi.org/10.1038/s41467-018-04998 -9 (2018).

71. Hunter, A. C. Molecular hurdles in polyfectin design and mechanistic background to polycation induced cytotoxicity. Adv. Drug Deliv. Rev. 58, 1523-1531. https://doi.org/10.1016/j.addr.2006.09.008 (2006).

72. Verheul, R. J. et al. Influence of the degree of acetylation on the enzymatic degradation and in vitro biological properties of trimethylated chitosans. Biomaterials 30, 3129-3135. https://doi.org/10.1016/j.biomaterials.2009.03.013 (2009).

73. Mariani, E., Lisignoli, G., Borzi, R. M. \& Pulsatelli, L. Biomaterials: foreign bodies or tuners for the immune response?. Int. J. Mol. Sci. 20, 636. https://doi.org/10.3390/ijms20030636 (2019).

74. Azam, A. et al. Antimicrobial activity of metal oxide nanoparticles against Gram-positive and Gram-negative bacteria: a comparative study. Int. J. Nanomed. 7, 6003-6009. https://doi.org/10.2147/IJN.S35347 (2012).

75. Hasan, A. et al. Nanoparticles in tissue engineering: applications, challenges and prospects. Int. J. Nanomed. 13, 5637-5655. https://doi.org/10.2147/IJN.S153758 (2018).

76. Sallusto, F. \& Lanzavecchia, A. The instructive role of dendritic cells on T-cell responses. Arthritis Res. Therapy 4, 127-132. https ://doi.org/10.1186/ar567 (2002)

77. Blanco, P., Palucka, A. K., Pascual, V. \& Banchereau, J. Dendritic cells and cytokines in human inflammatory and autoimmune diseases. Cytokine Growth Factor Rev. 19, 41-52. https://doi.org/10.1016/j.cytogfr.2007.10.004 (2008).

78. Chaturvedi, A. et al. Evaluation of poly (vinyl alcohol) based cryogel-zinc oxide nanocomposites for possible applications as wound dressing materials. Mater. Sci. Eng. C Mater. Biol. Appl. 65, 408-418. https://doi.org/10.1016/j.msec.2016.04.054 (2016).

79. Gholipourmalekabadi, M. et al. Chapter 12-Oxygen-generating nanobiomaterials for the treatment of diabetes: a tissue engineering approach. Nanobiomater. Soft Tissue Eng. 5, 331-353. https://doi.org/10.1016/B978-0-323-42865-1.00012-X (2016).

80. Camci-Unal, G., Alemdar, N., Annabi, N. \& Khademhosseini, A. Oxygen releasing biomaterials for tissue engineering. Polym. Int. 62, 843-848. https://doi.org/10.1002/pi.4502 (2013).

81. Peng, M. \& Kuc, J. Peroxidase-generated hydrogen peroxide as a source of antifungal activity in vitro and on tobacco leaf disks. Phytopathology 82, 696-699. https://doi.org/10.1094/phyto-82-696 (1992).

82. Roberts, C. \& Antonoplos, P. Inactivation of human immunodeficiency virus type 1, hepatitis A virus, respiratory syncytial virus, vaccinia virus, herpes simplex virus type 1 , and poliovirus type 2 by hydrogen peroxide gas plasma sterilization. Am. J. Infect. Control 26, 94-101. https://doi.org/10.1016/s0196-6553(98)80028-x (1998).

83. Siqueira, J. F. \& Lopes, H. P. Mechanisms of antimicrobial activity of calcium hydroxide. Int. Endod. J. 32, 361-369. https://doi. org/10.1046/j.1365-2591.1999.00275.x (1999).

84. Sathorn, C., Parashos, P. \& Messer, H. Antibacterial efficacy of calcium hydroxide intracanal dressing: a systematic review and meta-analysis. Int. Endod. J. 40, 2-10. https://doi.org/10.1111/j.1365-2591.2006.01197.x (2007).

85. Mohammadi, Z., Shalavi, S. \& Yazdizadeh, M. Antimicrobial activity of calcium hydroxide in endodontics: a review. Chonnam Med. J. 48, 133-140. https://doi.org/10.4068/cmj.2012.48.3.133 (2012).

86. Khakimova, M., Ahlgren, H. G., Harrison, J. J., English, A. M. \& Nguyen, D. The stringent response controls catalases in Pseudomonas aeruginosa and is required for hydrogen peroxide and antibiotic tolerance. J. Bacteriol. 195, 2011-2020. https://doi. org/10.1128/JB.02061-12 (2013).

87. Hixon, K. R., Lu, T. \& Sell, S. A. A comprehensive review of cryogels and their roles in tissue engineering applications. Acta Biomater. 62, 29-41. https://doi.org/10.1016/j.actbio.2017.08.033 (2017).

88. Villard, P. et al. Autoclavable and injectable cryogels for biomedical applications. Adv. Healthc. Mater. 8, e1900679. https://doi. org/10.1002/adhm.201900679 (2019).

89. Johnson, C. T. \& Garcia, A. J. Scaffold-based anti-infection strategies in bone repair. Ann. Biomed. Eng. 43, 515-528. https://doi. org/10.1007/s10439-014-1205-3 (2015).

90. Travan, A. et al. Non-cytotoxic silver nanoparticle-polysaccharide nanocomposites with antimicrobial activity. Biomacromol 10, 1429-1435. https://doi.org/10.1021/bm900039x (2009).

91. Yuan, S. et al. Nuclease-functionalized poly(styrene-b-isobutylene-b-styrene) surface with anti-infection and tissue integration bifunctions. ACS Appl. Mater. Interfaces 6, 18078-18086. https://doi.org/10.1021/am504955g (2014).

92. Wang, Y. S. G., Swartjes, J., van der Mei, H. C., Busscher, H. J. \& Libera, M. Length-scale mediated differential adhesion of mammalian cells and microbes. Adv. Funct. Mater. 21, 3916-3923. https://doi.org/10.1002/adfm.201100659 (2011).

93. Urban, M. V., Rath, T. \& Radtke, C. Hydrogen peroxide (H2O2): a review of its use in surgery. Wien Med Wochenschr https:// doi.org/10.1007/s10354-017-0610-2 (2017).

94. Martinez, Y. N., Cavello, I., Hours, R., Cavalitto, S. \& Castro, G. R. Immobilized keratinase and enrofloxacin loaded on pectin PVA cryogel patches for antimicrobial treatment. Bioresour. Technol. 145, 280-284. https://doi.org/10.1016/j.biortech.2013.02.063 (2013).

95. Bagri, L. P., Bajpai, J. \& Bajpai, A. K. Evaluation of starch based cryogels as potential biomaterials for controlled release of antibiotic drugs. Bull. Mater. Sci. 34, 1739-1748 (2011).

96. Tian, R. et al. Fabrication of self-healing hydrogels with on-demand antimicrobial activity and sustained biomolecule release for infected skin regeneration. ACS Appl. Mater. Interfaces 10, 17018-17027. https://doi.org/10.1021/acsami.8b01740 (2018).

97. Shin, D. H., Choi, Y. S. \& Cho, Y. H. Unusual properties of catalase A (KatA) of Pseudomonas aeruginosa PA14 are associated with its biofilm peroxide resistance. J. Bacteriol. 190, 2663-2670. https://doi.org/10.1128/JB.01580-07 (2008).

98. Newland, B., Baeger, M., Eigel, D., Newland, H. \& Werner, C. Oxygen-Producing gellan gum hydrogels for dual delivery of either oxygen or peroxide with doxorubicin. ACS Biomater. Sci. Eng. 3, 787-792 (2017).

99. Memic, A. et al. Hydrogels 2.0: improved properties with nanomaterial composites for biomedical applications. Biomed. Mater. 11, $014104(2015)$.

100. Camci-Unal, G., Alemdar, N., Annabi, N. \& Khademhosseini, A. Oxygen-releasing biomaterials for tissue engineering. Polym. Int. 62, 843-848 (2013).

101. Bryers, J. D., Giachelli, C. M. \& Ratner, B. D. Engineering biomaterials to integrate and heal: the biocompatibility paradigm shifts. Biotechnol. Bioeng. 109, 1898-1911. https://doi.org/10.1002/bit.24559 (2012).

102. Anderson, J. M., Rodriguez, A. \& Chang, D. T. Foreign body reaction to biomaterials. Semin. Immunol. 20, 86-100. https://doi. org/10.1016/j.smim.2007.11.004 (2008).

103. Rezaeeyazdi, M., Colombani, T., Memic, A. \& Bencherif, S. A. Injectable hyaluronic acid-co-gelatin cryogels for tissue-engineering applications. Materials (Basel) https://doi.org/10.3390/ma11081374 (2018). 
104. Shirbin, S. J. et al. Polypeptide-based macroporous cryogels with inherent antimicrobial properties: the importance of a macroporous structure. ACS Macro Lett. 5, 552-557. https://doi.org/10.1021/acsmacrolett.6b00174 (2016).

105. Bencherif, S. A. et al. Injectable cryogel-based whole-cell cancer vaccines. Nat. Commun. 6, 7556. https://doi.org/10.1038/ncomm s8556 (2015).

\section{Acknowledgements}

S.A.B. acknowledges the support from Northeastern University Seed Grant/Proof of Concept Tier 1 Research Grant, Burroughs Wellcome Fund award (1018798), Thomas Jefferson/Face foundation award, DFCI/NU Joint Program Grant, and NSF CAREER award (DMR 1847843). S.A.B. and A.M. acknowledge the support from the National Plan for Science, Technology and Innovation (MAARIFAH), King Abdulaziz City for Science, and Technology, the Kingdom of Saudi Arabia, award (15-MED5025-03). The authors also, acknowledge with thanks the Science and Technology Unit, King Abdulaziz University for the technical support. T.J.W. acknowledges the Art Zafiropoulo endowment for the bacterial studies.

\section{Author contributions}

K.J.N. and S.A.B. conceived and designed the experiments. K.J.N., T.C., M.R., and D.R. performed the experiments (biomaterials synthesis and characterization, in vitro and in vivo studies). K.J.N., N.B., and T.J.W. assisted with the microbiology experiments (bacterial studies). K.J.N., A.M., and S.A.B. analyzed the data and wrote the manuscript. All authors discussed the results and commented the manuscript. The principal investigator is S.A.B.

\section{Competing interests}

The authors declare no competing interests.

\section{Additional information}

Supplementary information is available for this paper at https://doi.org/10.1038/s41598-020-75196-1.

Correspondence and requests for materials should be addressed to S.A.B.

Reprints and permissions information is available at www.nature.com/reprints.

Publisher's note Springer Nature remains neutral with regard to jurisdictional claims in published maps and institutional affiliations.

(c) (1) Open Access This article is licensed under a Creative Commons Attribution 4.0 International cc) License, which permits use, sharing, adaptation, distribution and reproduction in any medium or format, as long as you give appropriate credit to the original author(s) and the source, provide a link to the Creative Commons licence, and indicate if changes were made. The images or other third party material in this article are included in the article's Creative Commons licence, unless indicated otherwise in a credit line to the material. If material is not included in the article's Creative Commons licence and your intended use is not permitted by statutory regulation or exceeds the permitted use, you will need to obtain permission directly from the copyright holder. To view a copy of this licence, visit http://creativecommons.org/licenses/by/4.0/.

(C) The Author(s) 2020 